\title{
Axial skeleton anterior-posterior patterning is regulated through feedback regulation between Meis transcription factors and retinoic acid
}

Alejandra C. López-Delgado ${ }^{1, \dagger}$, Irene Delgado ${ }^{1}$, Vanessa Cadenas ${ }^{1}$, Fátima SánchezCabo $^{2}$ and Miguel Torres ${ }^{1, *}$

${ }^{1}$ Cardiovascular Development Program and ${ }^{2}$ Bioinformatics Unit, Centro Nacional de Investigaciones Cardiovasculares (CNIC), Madrid, Spain

${ }^{*}$ Corresponding author

${ }^{\dagger}$ Current address: Center for Regenerative Therapies, TU Dresden, Germany 


\section{ABSTRACT}

Vertebrate axial skeletal patterning is controlled by coordinated collinear expression of Hox genes and axial level-dependent activity of Hox protein combinations. Transcription factors of the Meis family act as cofactors of Hox proteins and profusely bind to Hox complex DNA, however their roles in mammalian axial patterning have not been established. Similarly, retinoic acid $(R A)$ is known to regulate axial skeletal element identity through the transcriptional activity of its receptors, however, whether this role is related to Meis/Hox activity in axial patterning remains unknown. Here we study the role of Meis in axial skeleton formation and its relationship to the RA pathway by characterizing Meis1, Meis2 and Raldh2 mutant mice. Meis elimination produces axial skeleton defects without affecting Hox gene transcription, including vertebral homeotic transformations and rib mis-patterning associated to defects in the hypaxial myotome. While Raldh2 and Meis positively regulate each other, Raldh2 elimination largely recapitulates the defects associated to Meis-deficiency and Meis overexpression rescues the axial skeletal defects in Raldh2 mutants. We propose a Meis-RA positive feedback loop whose output is Meis levels and is essential to establish anterior-posterior identities and pattern of the vertebrate axial skeleton. 


\section{INTRODUCTION}

Anterior-posterior (AP) patterning is an essential feature of the bilaterian body plan and its mechanisms have been extensively studied. Canonical examples of AP patterning in vertebrates are found in the hindbrain and in the axial musculoskeletal system (Krumlauf, 1994). Segmental epithelial sacs known as somites emerge from the paraxial mesoderm as it is produced and progressively incorporate to the AP axis. The initially homogeneous somites later subdivide in compartments, including the sclerotome, precursor of the vertebrae and ribs, and the myotome, precursor of the skeletal muscles (Musumeci et al., 2015). Crosstalk from the myotome to the sclerotome is essential for sclerotome patterning and in particular for rib specification and patterning (Vinagre et al., 2010).

An important breakthrough in understanding antero-posterior axis patterning was the identification of Hox mutants in Drosophila, which cause the transformation of one part of the body into another, a phenomenon known as homeotic transformation (Lewis, 1978). Hox genes are conserved in evolution and appear organized in genetic complexes in most animals (Duboule and Dolle, 1989; Sanchez-Herrero et al., 1985). Mammals show Hox genes organized in 4 paralogous complexes ( $\operatorname{Hox} A, B, C$ and $D)$ that originated from two consecutive rounds of genome duplication and contain up to 13 paralogous genes. The genomic organization of Hox complexes correlates with their temporal and spatial expression domains, a phenomenon known as collinearity (Gaunt et al., 1986; Lewis, 1978). Mutations in Hox genes in different species produce AP homeotic transformations, which in mammals is best exemplified in the hindbrain and in the axial skeleton (Krumlauf, 1994).

Hox gene transcription is activated sequentially in axial precursors during gastrulation (13). Expression of Hox genes located at the 3'-most region of the complexes starts in axial progenitors in the posterior epiblast and is maintained in their descendants as they gastrulate through the primitive streak and colonize the embryonic AP axis. 3'-to-5' sequential transcriptional activation of Hox complexes progresses continuously in axial progenitors, whereas their daughter cells fix their Hox expression code as they exit the progenitor region and colonize the embryonic axis. As cells colonize the different AP segments, they carry the successive Hox expression combinations to the progressively forming body axis, resulting in an AP nested patterns (Alexander et al., 2009). Thus, temporal information is translated into spatial domains during axial elongation (Deschamps and Duboule, 2017).

Hox proteins bind DNA through a 60 amino acid region called the homeodomain (McGinnis et al., 1984). The homeodomain is highly conserved and diversified in several transcription factor families in animals and plants. Hox proteins alone show limited DNA- 
binding ability, but they gain specificity and affinity for target sequences through interactions with cofactors of the PBC and MEINOX families, both belonging to the three amino acid loop extension (TALE) class of homeodomains (Mann and Affolter, 1998). PBC and MEINOX proteins form heterodimers and heterotrimers with Hox proteins, conferring them with increased target sequence selectivity and affinity (Merabet and Mann, 2016). In fact, mutants for the single members of the PBC and MEINOX families in Drosophila show AP phenotypes compatible with a generalized Hox loss of function, without affecting Hox AP expression (Chan et al., 1994; Rieckhof et al., 1997). In mammals, redundancy of the PBC (4 members) and MEINOX (5 members) families has hampered the study of their roles in axial skeletal patterning. While knowledge has been obtained from $\mathrm{Pbx}$ mutants in zebrafish and mouse, indicating essential roles in axial skeleton patterning (Capellini et al., 2008; Popperl et al., 2000; Selleri et al., 2001), the role of Meis genes in this context remains unexplored.

Meis proteins directly bind Hox proteins encoded by paralogs 9-13 (Shen et al., 1997) and form DNA-bound heterotrimeric complexes with $\mathrm{Pbx}$ and Hox proteins encoded by paralogs 1-10 (Chang et al., 1996). The repertoire of Meis, Prep and Pbx binding sites by ChIP-seq analysis in E11.5 mouse embryos identified Hox and Hox-PBC binding sites as the preferred sites for Meis binding, above the Meis-only binding sites, suggesting that Meis factors are strongly dedicated to interactions with $\mathrm{Hox}$ and $\mathrm{Pbx}$ proteins (Penkov et al., 2013). In addition, a large number of Meis binding sites was found within the Hox complexes, which suggested that additionally to their Hox-cofactor role, they may regulate Hox transcription. Studies in zebrafish (Choe et al., 2014) and mouse (Amin et al., 2015) embryos indeed showed that some of these binding sites represent Hox auto-regulatory elements active in the neural tube and Hox transcription regulation by Meis factors has been demonstrated in neural tube patterning (Dibner et al., 2001; Vlachakis et al., 2001; Waskiewicz et al., 2001). Meis elimination or overexpression also affects Hox gene expression during limb skeletal patterning (Delgado et al., 2020; Mercader et al., 1999; Mercader et al., 2009; Rosello-Diez et al., 2014), however , this aspect has not been studied in axial skeleton patterning.

Another interesting pathway that connects Meis, Hox and axial patterning is that of vitamin-A. The active form of Vitamin-A, retinoic acid (RA), regulates gene expression during embryonic development by binding to nuclear receptors RARa, RAR $\beta$ or RARY (Rhinn and Dolle, 2012). Meis genes have been identified in screens for RA targets (Berenguer et al., 2020; Oulad-Abdelghani et al., 1997) and respond to RA fluctuations in vivo (Mercader et al., 2000). RA excess produces axial skeleton alterations and modifies the Hox AP expression domains (Kessel and Gruss, 1991) and mutations in RA-receptor genes result in homeotic transformations, however, the mechanism by 
which this takes place is not clear. While RAR binding sites have been described in Hox complexes (Marshall et al., 1996), and RA administration in vitro regulates Hox gene transcription (Deschamps et al., 1987), RA administration in vivo can lead to axial skeleton homeotic transformations without changes in Hox expression (Kessel, 1992) and changes in Hox expression in Rar-deficient mice have not been reported.

Here we study the role of Meis factors in axial skeleton formation and its relationship to the RA pathway by characterizing mouse genetic models of Meis1, Meis2 and Raldh2. We dissect the regulatory and functional relationships between Meis, Hox and Raldh2 and formulate a new model that explains the ability of RA to produce homeotic transformations without modifying Hox expression.

\section{RESULTS}

\section{Meis gene expression during anterior-posterior axial patterning of the mouse embryo}

We studied the mRNA expression pattern of Meis1 and Meis2, the two Meis genes extensively expressed in paraxial and lateral mesoderm (Figure 1). We detected the earliest expression of Meis2 in early-streak stage embryos in a posterior region of the embryo close to the boundary with the extraembryonic region (Figure $1 \mathrm{H}$ ). This expression extends distally and anteriorly as development progresses (Figure 1I) and at the early-headfold stage, an anterior stripe of Meis2 transcripts was found bilaterally close to the extraembryonic region, and continuous with its posterior expression (Figure $1 \mathrm{~J})$. At late-headfold stage, Meis2 started to disappear from the posterior region (Figure $1 \mathrm{~K}$ ) and at E8, the posterior embryonic bud was devoid of Meis2 transcripts (Figure 1L). Meis1 expression started slightly later than Meis2, being first detected at the late-streak stage, bilaterally in the mesoderm close to the extraembryonic region (Figure 1B) and at the early-headfold stage, forming a stripe of expression, similar to Meis2 anterior stripe at this stage (Figure 1C). Both Meis1 and Meis2 expression domains extend posteriorly into the lateral plate mesoderm at the late-headfold stage (Figure $1 \mathrm{D}$ and $1 \mathrm{~K}$ ), but high levels of Meis1 transcripts were never observed in the posterior embryonic bud. Finally, at E8 Meis1 and Meis2 expression patterns converge to a similar expression pattern, being strongly expressed in paraxial and lateral plate mesoderm up to the pharyngeal region (Figure 1E and $1 \mathrm{~L}$ ). At this stage, expression of both genes is excluded from the posterior embryonic bud, whereas it appears in the presomitic mesoderm and adjacent regions precursor to the lateral plate mesoderm. This expression pattern is maintained at later stages, indicating that as new precursors from the posterior bud incorporate to 
the presomitic area, they activate Meis1 and Meis2 and this activity persists as they differentiate into paraxial and lateral plate mesoderm. To determine the early activation pattern of Meis1 and Meis2 in the embryonic germ layers, we studied Meis mRNA and protein distribution in sections (Figure 1). Detection of Meis proteins in sections with an antibody that recognizes the majority of embryonic isoforms but does not discriminate between Meis1 and Meis2 shows early expression in all three germ layers at early allantoic bud stage (Figure $1 \mathrm{G}$ and $1 \mathrm{~N}$ ). Sections of the RNA in situ hybridization of both genes, showed that Meis1 expression was not detected in the epiblast/ectoderm (Figure 1F), while Meis2 expression affected the three germ layers (Figure 1M). This result suggests Meis2 is activated in epiblast cells and its expression persists as they gastrulate to contribute to mesoderm. The early Meis 2 expression pattern thus resembles the activation pattern of Hox genes.

\section{Meis loss of function produces axial skeletal defects, including antero-posterior homeotic transformations}

We used conditional deletion of Meis1 and Meis2 and studied the mutant skeletal pattern. We first studied the consequences of Meis2 deletion using different Cre alleles that allow dissecting the putative specific functions of Meis2 early expression. Deletion of a Meis $2^{\text {flox }}$ allele with Sox ${ }^{\text {Cre }}$ leads to Meis2 elimination in the epiblast. Lethality of Sox ${ }^{\text {Cre }}$;Meis $2^{\text {flox/flox }}$ embryos around E14.5-E15.5 due to cardiac defects did not allow us to study the pattern at later stages; however, the general vertebral formula could be determined at E14.5. We observed defects at the occipital-cervical transition, where the first cervical vertebra ( $C 1$ or atlas) was fused to the exoccipital bone $(n=14 / 14)$ and in its ventral part showed a position and shape that resemble the exoccipital bone, while its dorsal part was not formed (Figure 2A and 2B; S1A Table). These changes correlated with a change in the shape of the second vertebra (C2 or axis), which acquired a $\mathrm{C} 1$-like morphology $(n=13 / 14)$ (Figure $2 A$ and $2 B$ ). With low penetrance, the C3 vertebra presented a morphology that resembles $C 2 \quad(n=2 / 14)$. These observations are compatible with an anterior homeotic transformation of the cervical vertebrae. In addition, disconnected isolated elements often appeared (arrowhead in Figure 2B), suggesting as well segmentation problems in this region. Outside the axial skeleton, we observed a vestigial otic capsule in the mutants.

In the thoracic region, the most prominent defect was rib, rib-sternum attachment and sternum mispatterning (Figure 2D and $E$ ). We observed failures in sternum fusion, rib bifurcations, fusions and alteration of the sternal/floating rib formula. The gain of a rib in the first lumbar vertebra $(L 1)$ in some specimens $(n=4 / 14)$ and the tendency to reduction 
of the first rib (R1) suggests the anterior transformations observed in the cervical region may also affect the thoracic region (Figure 2B). More caudal regions did not show any defects.

To investigate if Meis2 activity in the epiblast is involved in the observed defects, we combined the Meis $2^{\text {flox }}$ allele with $M e s p 1^{\text {Cre }}$ to eliminate Meis2 from the nascent mesoderm. While Mesp1 activates in the early embryo in a similar pattern to Meis2, because of the time lag between Cre expression and effective recombination, the recombination pattern of Mesp $1^{\text {Cre }}$ affects only the mesoderm and it does so down to the forelimb level (Saga et al., 1999). As it occurred with Sox $2^{\text {Cre }}$;Meis $2^{\text {floxfllox }}$ mice, lethality due to cardiac defects only allowed us to study the phenotype at E14.5. In the Mesp ${ }^{\text {Cre }}$ model, we observed lower penetrance, but the same type and distribution of defects found in the Sox ${ }^{\text {Cre }}$ model, excepting the reduction of R1 and the otic capsule defects (Figure 2C and 2F; S1A Table).

To further dissect the specific tissues in which Meis2 activity is required during early embryogenesis, we studied a third model in which we deleted Meis $2^{\text {flox }}$ using DII1 ${ }^{\mathrm{Cre}}$, a line that recombines the mesoderm in the presomitic region (Wehn et al., 2009), i.e., at a later step of mesodermal allocation than Mesp $1^{\text {Cre }}$ does. Dll1 ${ }^{\text {Cre }} ;$ Meis $2^{\text {flox/flox }}$ mice survive to adulthood, allowing a full assessment of the skeletal pattern at the end of gestation. In this model, we observed similar defects as those previously observed in the Sox $2^{\text {Cre }}$ and Mesp $1^{\text {Cre }}$ models in the occipital, cervical and thoracic regions (Figure 2G$\mathrm{N}$ and 3M; S1A Table). In addition, we observed a defect in supraoccipital ossification (Figure $2 \mathrm{~K}, 2 \mathrm{M}$ and $3 \mathrm{M}$ ) and fusions between the basioccipital and the anterior arch of the atlas (aaa) (Figure 2G, 2I and 3M), which could not be determined at earlier stages because these bones form late in gestation. Again, we did not detect the formation of a rib in L1, suggesting this phenotype requires an early deletion of Meis2.

The irrelevance of early Meis2 expression for most aspects of axial patterning is not due to compensatory activation of Meis 1, as we detected no ectopic Meis 1 mRNA expression in early Sox ${ }^{\text {Cre }}$;Meis2 $2^{\text {floxfllox }}$ embryos (S1 Figure). These results indicate that the expression of Meis2 in the epiblast and early nascent mesoderm is to a large extent dispensable for its functions in axial skeletal patterning, although it might be needed for a proper specification of the thoracic-to-lumbar transition.

Next, to determine whether Meis 1 and Meis2 cooperate in axial patterning, we combined Meis1 and Meis2 mutant alleles. Combining Meis1 and Meis2 deletion is not possible using the Sox $2^{\text {Cre }}$ or the Mesp $1^{\text {Cre }}$ deleters, due to lethality of double heterozygous mice. We therefore used the DII1 ${ }^{\text {Cre }}$ line for these experiments. The defects observed in the allelic series generated affected the same skeletal elements that were altered in the Meis2 mutant models (Figure 3 ) and the type of defects were similar, with anterior 
transformations of C1-C3 (Figure 3G-I and 3M; S1B Table) and defects in the occipital bones that either did not form or appeared fused to $\mathrm{C} 1$ or $\mathrm{C} 2$ element (Figure 3A-I and 3M; S1B Table). In the thoracic region we also detected rib fusions and defects in ribsternum attachment (Figure 3J-L and 3M; S1B Table). Although we found 2 cases of extra ribs on $\mathrm{L} 1$, one case was also found in controls, suggesting this observation was unspecific. In general, skeletal defects are more severe as the number of Meis alleles deleted increases, being the absence of Meis2 more detrimental than Meis1 (Figure 3M; S1B Table). However, for some aspects of the phenotype, E18.5 $D / l 1^{\text {Cre }}$;Meis $1^{\text {floxfllox}}$;Meis $2^{\text {floxfllox }}$ specimens appeared less affected in comparison with $D I / 1^{\text {Cre }}$;Meis $1^{\text {+fflox}}$;Meis $2^{\text {floxflox }}$ ones, which was paradoxical. We observed, however, that the viability of DII ${ }^{\text {Cre }} ;$ Meis $1^{\text {flox/flox }} ;$ Meis $2^{\text {floxflox }}$ mice at E18.5 was $37 \%$, which suggested that specimens of this genotype at E18.5 represent escapers and thus, missing specimens could be more affected than appreciated. We then studied the phenotype of DII1 ${ }^{\text {Cre }}$ :Meis $1^{\text {floxfllox}} ;$ Meis $2^{\text {flox/flox }}$ fetuses at E14.5, when viability of double mutants was $67 \%$, and observed a fraction of embryos with defects compatible with those observed at E18.5 and, in addition, we found very strongly affected fetuses showing all the cervical vertebrae fused, no apparent development of occipital condensations and widespread rib fusions and truncations (Figure $3 \mathrm{~N}$ and $3 \mathrm{O}$ ). In addition to the axial skeleton, defects in the limb skeleton were obvious in DII1 ${ }^{\text {Cre }}$;Meis $1^{\text {floxflox; }}$;Meis $2^{\text {floxfflox }}$ fetuses (Figure $3 \mathrm{~N}$ and 30) and have been independently reported (Delgado et al., 2020).

\section{Hox mRNA axial expression in Meis mutants}

While defects in vertebral segmentation or overt rib deformations have not been described in Hox mutants, the AP specification defects observed in the occipital and cervical regions are very similar to those observed in the mutants of Hox paralog groups $3-5$, and some of the rib cage defects are similar to those found in paralog groups 5-9 (Horan et al., 1995; Jeannotte et al., 1993; Manley and Capecchi, 1997; McIntyre et al., 2007). These coincidences and the previous reports of Meis proteins binding to Hox clusters (Amin et al., 2015; Penkov et al., 2013) prompted us to study the Hox mRNA expression pattern in Meis mutants. We did not detect alterations of Hox expression initiation or definitive anterior expression borders in either Sox $2^{C r e}$;Meis $2^{\text {floxflox }}$ or $D I / 1^{\text {Cre }}$;Meis $1^{\text {flox/flox }}$;Meis2 $2^{\text {flox/flox }}$ embryos (Figure 4A and 4B). These results indicate that eliminating Meis2 function with Sox $2^{\text {Cre }}$ or Meis1 and Meis2 DII1 ${ }^{\text {Cre }}$ does not modify Hox expression patterns and therefore, the phenotypes observed in these models do not relate to a Meis role in regulating Hox transcription. To study the generality of these observations, we combined simultaneous maternal and paternal deletion of Meis $1^{\text {floxflox }}$ and Meis $2^{\text {floxfllox }}$ alleles, using the maternal deleter $\mathrm{Zp} 3^{\mathrm{Cre}}$ and the paternal deleter 
Stra8 ${ }^{\text {Cre }}$ (S2 Figure). With this approach, we were able to completely eliminate Meis1 and Meis2 zygotic expression. Such embryos die around E9 with profound alterations of cardiac development, however this allowed us to study early Hox expression patterns. While previous reports in embryos at E9.5 or later stages have described paralog group Hox3 gene expression starting at somite 5 (Alexander et al., 2009), we found that in control embryos of up to 10 somites, expression of the Hox3 paralog group extends from somite 2-3 into more posterior somites (Figure 4C; S3 Figure). In embryos of 12 somites, the most anterior expressing somite is somite 3-4, while in embryos of more than 15 or more somites, expression starts at somite 5. These observations show transient Hox3 expression in occipital somites and a later progressive posteriorization towards their definitive expression domain. This expression pattern agrees with the fact that mutants of the group-3 Hox genes strongly affect the occipital region, which is mostly originated from somites 1-4. The defects present in group-3 Hox mutants in fact strongly affect the supraoccipital bone, which is exclusively contributed by somites 1 and 2 (Huang et al., 2001; Muller and O'Rahilly, 1994). Mutant embryos showed a normal Hox3-group gene expression in the paraxial mesoderm of embryos of 4-10 somites (Figure 4C; S3 Figure). Although counting somites was very difficult in mutant embryos of $15-20$ somites, due to the developmental abnormalities, we concluded that the expression patterns in the paraxial mesoderm were either normal or anteriorized by 1-2 somites (Figure 4C; S3 Figure). In contrast, the anterior border of expression in the neural tube appeared clearly posteriorized (Figure 4C; S3 Figure). The study of the expression of hoxd4 showed similar results, with a transient early expression starting at somite 4 and later getting restricted to its definitive anterior border at somite 6 . In mutants, hoxd4 expression was similar at early stages and appeared anteriorized to somite 4-5 at later stages. A posteriorization of Hox mRNA expression in the neural tube was again evident (Figure 4C). Most likely, the failure observed in the mutants in relocating Hox expression to more posterior somites at late stages does not indicate a direct role of Meis in regulating Hox expression, but a general blockade in development of Meis DKO embryos beyond the somite-7 stage. In fact, Meis DKO embryos do not undergo turning, body wall folding or neural tube closure, morphologically resembling E8.5 embryos at E9. The fact that no alterations were observed upon deletion with DII1 ${ }^{\text {Cre }}$ support this conclusion.

We therefore conclude that transcriptional regulation of Hox genes is not involved in Meis regulation of axial skeleton patterning.

\section{Meis activity is required for hypaxial myotomal development}

To identify the molecular mechanism underlying the skeletal phenotypes observed, we performed a transcriptomic analysis of E9 DII1 ${ }^{\text {Cre }} ;$ Meis $1^{\text {floxflox }}$;Meis $2^{\text {flox/flox }}$ embryos. To 
discriminate between alterations during the somite differentiation phase and early patterning defects, we separately analyzed the anterior region containing the first 10-12 somites and the posterior region including the rest of the somites and the posterior embryonic bud. We identified 9 upregulated genes and 25 downregulated genes in the analysis of the anterior region; whereas in the posterior region there were 58 upregulated and 58 downregulated genes (S4A and S4B Figure). Ingenuity Pathway Analysis showed that "skeletal and muscular system development" appears as the top tissuespecific altered class Figure S4C). Differences in other processes such as cell death, cell-to-cell interactions, cell assembly and organization were also found in this analysis (S4C Figure). No alterations were found in Hox gene expression, which confirmed the results observed in the Hox mRNA in situ analysis.

We then focused on the in situ analysis of genes involved in somite development found altered in the RNAseq analysis and in additional genes relevant to somite patterning. When comparing the expression pattern of this set of genes between control and $D I / 1^{\text {Cre }}$;Meis $1^{\text {flox/flox }}$;Meis $2^{\text {flox/flox }}$ embryos, we found that a set of genes expressed and/or involved in hypaxial myotomal development were downregulated in the hypaxial region of the mutants (Figure 5), including Eya1 (Grifone et al., 2007) (Figure 5A and 5B), Sim1 (Ikeya and Takada, 1998) (Figure 5C and 5D), Shisa2 (Nagano et al., 2006) (Figure 5E and 5F) and Pax3 (Tremblay et al., 1998) (Figure 5G and 5H).

Regarding sclerotome markers, we found no alteration of Pax1 expression (Figure $5 \mathrm{I}$ and 5J); however, an abnormal expression pattern of Pax9 was observed in sclerotomes of the cervical region, which appeared incorrectly segmented (Figure $5 \mathrm{~K}$ and $5 \mathrm{~L}$ ).

Crosstalk between the myotome and sclerotome is essential for proper rib patterning and mice deficient for the myogenic factors Myf5 (Braun et al., 1992), MRF4(Zhang et al., 1995), or Myogenin (Vivian et al., 2000) show rib defects that resemble those described here in Meis mutants. Therefore, we next studied the main myogenic factors. Expression of Myf5 appears first in the epaxial somite at E8, followed by MRF4 and Myogenin at E9, later extending hypaxially caudal to the forelimb at E10.5 (Figure 5M$\mathrm{R})$. In mutant mice, the early epaxial expression of Myf5 shows incomplete segmentation, whereas at E10.5, expression in myotomes anterior to the forelimb extends ventrally and appears as a continuous band between adjacent somites in a pattern that is not detected in control embryos (Figure $5 \mathrm{M}$ and $5 \mathrm{~N}$ ). Both MRF4 and Myogenin show mis-segmented and bifurcating patterns in mutant embryos (Figure 5 O$\mathrm{R})$. In addition, the ventral hypaxial extension of the expression domain was reduced, as observed before for other hypaxial markers. In contrast, defects in the early expression of Myogenin at E9 are not as evident as for Myf5. MyoD shows as well a disorganized 
and spread expression in cervical myotomes of mutants, whereas hypaxial extension of the expression is also defective in more caudal myotomes (Figure 5T).

We finally studied FGF4 and FGF6, which are involved myogenesis through their expression in the medial myotome (Grass et al., 1996). We found that expression of FGF4 and FGF6 appeared highly reduced in mutant embryos (Figure $5 \mathrm{U}-\mathrm{X}$ ).

In summary, re-segmentation of the paraxial mesoderm appears impaired in Meis mutants, with defects in the separation of adjacent sclerotomal/myotomal domains and bifurcated myogenic domains. These defects affect mainly the cervical region, although defects were also seen some times in the interlimb region. During further myotome development, a defect in myogenic FGF expression was found and the hypaxial developmental program seems especially affected with a failure in hypaxial myotomal migration, in correlation with an inability to properly activate Pax3 expression.

\section{A positive feedback loop maintains the Retinoic Acid pathway and Meis expression during axial patterning.}

In the transcriptomic analysis of Meis mutants, Raldh2 -the gene encoding the main enzyme responsible for embryonic RA synthesis-, and Cyp26b1-the gene encoding the main enzyme responsible for RA degradation in the embryo- appeared downregulated in the anterior trunk region by RNA-seq (S4 Figure). In situ hybridizations for both genes were consistent with the transcriptomic analysis. Raldh2 expression appeared reduced at E9.5 in the differentiating derivatives of anterior somites but not in the presomitic area or in newly produced somites (Figure 6A-B"). A similar pattern is present at E10.5, where tail regions with newly produced somites do not show alterations but more anterior regions do show a reduction in Raldh2 transcripts (Figure 6C-D").

In the somitic region of E9 embryos, Cyp26b1 is expressed exclusively in the endothelium of the dorsal aortae and inter-somitic vessels, whereas it is strongly expressed in areas of the hindbrain. The hindbrain signal was preserved in mutants; however, the endothelial signal in the trunk region was lost (Figure 6E-F'). Cyp26b1 is a direct target of the RA pathway that gets activated in response to RA. The concomitant downregulation of Raldh2 and Cyp26b1 thus suggest that Meis mutant embryos are defective in RA. We then studied the expression of the gene encoding the RA receptor beta $(R A R \beta)$, which has been described as a RA-responsive gene. Contrary to expectations, no change in the pattern of $R A R \beta$ was detected between controls and Meis mutants (Figure 6G-H'), which is consistent with the RNAseq data that identified no differences in $R A R \alpha, R A R \beta$ or $R A R Y$.

Unexpectedly, several of the embryos studied showed Raldh2 reduction in a mosaic fashion. To understand why the reductions in Raldh2 appeared in a mosaic fashion, we 
combined Meis $1^{\text {flox }}$ and Meis $2^{\text {flox }}$ alleles with DII1 ${ }^{\text {Cre }}$ and a Rosa26R ${ }^{\text {tdTomato }}$ reporter. In these embryos, DII1 ${ }^{\text {Cre }}$ recombines the Rosa26R $R^{\text {tdTomato }}$ reporter, allowing to determine the Cre recombination pattern. At E10.5, E9.5 and E8.5, we observed a mosaic pattern of Tomato ${ }^{+}$cell distribution in both control and Meis mutant embryos, with variability in the proportion of Tomato ${ }^{+}$cells found in the somites of different embryos (Figure S5). This mosaicism had not been described for this line before (38) and therefore it might depend on the genetic background. To determine whether the observed mosaicism results from inefficient recombination in all cells or from mosaic activation of D/l $1^{\text {Cre }}$ expression, we studied the correlation between Meis immunodetection and Tomato

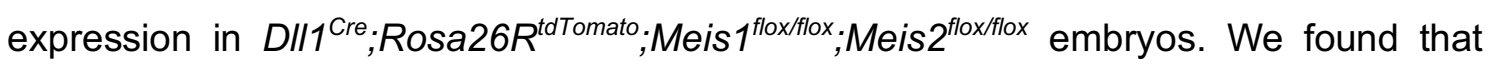
Tomato $^{+}$cells were devoid of Meis, while their neighboring Tomato- cells showed Meis expression (Figure 6I-J"). Image profiling shows anti-correlation between Tomato and Meis detection in mutants (Figure 6J'), whereas this was not found in control embryos (Figure 6l'). These observations indicate that the pattern observed results from mosaic inactivation of $D / 11^{\text {Cre }}$ and therefore the Tomato $^{+}$cell distribution reports the distribution of Meis-deficient cells. In mutants, we found a tendency of knockout and wild type cells to segregate from each other, resulting in large aggregates of Tomato $^{+}$cells that were not found in controls (Figure 6l' and 6J'). We did not find any reproducible difference between mutant and control embryos in the distribution of Tomato $^{+}$cell patches by tissues. In addition, the anterior-most border of Tomato $^{+}$cell distribution was established at the occipital level and this was not different between control and mutant embryos.

We therefore used the mosaic inactivation of Meis alleles to study the regulation of Raldh2 by Meis. We performed Raldh2 immunostaining and correlated this signal with that of Tomato. We found that Tomato $^{+}$cells lacking Meis function did not present detectable Raldh2 expression, while their Tomato-, Meis-expressing, neighboring cells showed normal Raldh2 expression (Figure 6K-L"). The result was similar to that observed for Meis immunostaining, being the signal of Raldh2 and Tomato mutually exclusive in mutant embryos but not in controls (Figure 6K" and 6L"). These results indicate a strict and cell-autonomous requirement of Meis function for Raldh2 expression in the differentiating trunk mesoderm.

We then analyzed Raldh2 expression in embryos with double maternal/zygotic inactivation of Meis1 and Meis2 (Figure 6M-R). Raldh2 mRNA distribution in the early embryo resembles Meis expression pattern; however, it starts slightly later and only affects the mesoderm (Figure S6). In mutant embryos, we observed no alteration of the expression pattern in the axial and paraxial mesoderm, however the lateral plate domain close to the extraembryonic region was abolished (arrowheads in Figure $6 \mathrm{M}$ and $6 \mathrm{~N}$ ). Up to E8.75, when only the first somites have formed, no alteration of Raldh2 expression 
in the paraxial mesoderm is observed (Figure $6 \mathrm{O}$ and $6 \mathrm{P}$ ), however at $\mathrm{E} 9$ all trunk Raldh2 expression is strongly decreased in mutants (Figure 6Q and 6R).

Given that retinoic acid has been shown to regulate Meis expression in different settings (Mercader et al., 2000; Oulad-Abdelghani et al., 1997; Yashiro et al., 2004), we studied whether the elimination Raldh2-mediated RA synthesis affects axial Meis expression. We studied Meis 1 and Meis2 mRNA and protein expression in Sox2 ${ }^{\text {Cre }}$; Raldh2 floxflox embryos and found that both genes presented a reduction of transcripts along the trunk region of E8 embryos (Figure 6S-V).

These results indicate that Meis is required for maintenance of Raldh2 expression in the differentiating paraxial mesoderm but not for its initial expression before somite differentiation. These conclusions correlate with the observed downregulation of Raldh2/Cyp26b1 in the transcriptome of anterior trunk but not the posterior trunk of E9.5 embryos. In contrast, the early lateral plate mesoderm -likely fated to the cardiogenic area- requires Meis activity for Raldh2 expression from the earliest stages. Reciprocally, Raldh2 expression is required to maintain proper Meis expression levels, but not for initiating Meis expression, given that Meis expression starts before Raldh2 expression. These results indicate that there is a positive regulatory loop between Meis and Raldh2 that is relevant to mutually maintain but not initiate their expression.

\section{Raldh2 deficiency produces axial skeleton defects partially overlapping with those observed in Meis mutants}

While retinoic acid has long been postulated as a regulator of axial skeleton, there is no direct study of the consequences of eliminating RA on antero-posterior axial identities. Here, we conditionally deleted Raldh2 using DI/1 ${ }^{\text {Cre }}$ to investigate whether this affects the axial skeleton and the extent to which RA might be related to Meis roles in axial patterning. In the occipital region, the basioccipital presented similar alterations to those observed in Meis mutants ( $n=14 / 43$ ) (Figure 7A and 7F; S1D Table), including its fusion with the aaa (Arrowhead in Figure 7F). Strikingly, similar modifications of the basioccipital were also found in some control embryos, although in a lower proportion $(n=5 / 47)$ (Figure 7P), suggesting a genetic background prone to these particular defects. In mutants, $\mathrm{C} 1$ appeared fused to, and/or adopting a shape and position similar to the exoccipital $(\mathrm{N}=8 / 49)$. In the cases in which $\mathrm{C} 1$ showed transformation to exoccipital, $\mathrm{C} 2$ adopted a $\mathrm{C} 1$ morphology $(n=8 / 41)$, whereas some cases in which $\mathrm{C} 1$ retained its morphology, C2 adopted a C1 morphology and partially fused to $C 1(n=9 / 41)$. C3 to $C 2$ transformations/fusions were also observed $(n=11 / 41)$. At the cervical thoracic transition, tuberculi anterior were found in $\mathrm{C} 7$ instead of $\mathrm{C} 6(\mathrm{n}=5 / 21)$ (Figure $7 \mathrm{C}$ and $7 \mathrm{H}$, arrow in $7 \mathrm{H}$ ), suggesting that anterior transformations also take place at this axial level. 
Altogether, the alterations found in Raldh2 mutants in the occipital/cervical regions were similar to those observed in Meis mutants but displayed lower penetrance (Figure 7P). In the thoracic region, shortening or fusion of the first rib with the second rib and generalized rib fusions and bifurcations were observed in similarity to the defects found in Meis mutants (Figure 7D and 7I). In the most affected mutant embryos, we observed defects in the inter-sternal cartilage and the sternebrae, although we did not observe a split sternum (Figure 7E and $7 \mathrm{~J}$ ). Some incidence of an extra sternal rib and an extra rib on L1 was also observed (Figure 7E, 7J and 7P), suggesting A-P transformations were extensive down to the thoracic/lumbar transition.

The compared analysis of Meis and Raldh2 mutants supports the idea that Meis and the retinoic acid pathway act in a positive feedback loop that is relevant in patterning the axial skeleton. To obtain evidence for the functional relevance of this regulatory loop and determine its relevant output in axial patterning, we used a Rosa26R ${ }^{\text {Meis2 }}$ allele that provides Meis2 overexpression upon Cre recombination. We then simultaneously eliminated Raldh2 and activated Meis2 with DII1 ${ }^{\text {Cre }}$. Interestingly, in this mouse model, all defects produced by Raldh2 mutation in the axial skeleton were rescued (Figure 7KO, 7P; S1D and S1E Table), indicating that Meis suppresses the effect of RA deficiency on axial skeleton patterning.

\section{DISCUSSION}

Meis1 and Meis2 expression starts at gastrulation, although their early patterns are different in time and expression domains. Meis2 is activated earlier than Meis1 in a pattern that coincides spatially and temporally with that of Hox gene activation in the posterior epiblast. Despite this, we have not observed alterations in Hox gene expression patterns or transcript abundance in Meis mutants. These results indicate that, despite the profuse binding of Meis proteins to the Hox complexes (Penkov et al., 2013), Meis is not involved in Hox gene transcriptional regulation during axial skeleton patterning. This is not extendable to other embryonic regions, given that we have observed clear alterations of Hox mRNA expression domains in limb buds with altered Meis function (Delgado et al., 2020; Mercader et al., 1999; Mercader et al., 2009; Rosello-Diez et al., 2014) and similar results have been reported in neural patterning (Dibner et al., 2001; Vlachakis et al., 2001; Waskiewicz et al., 2001). The observed binding of Meis to the Hox complexes therefore might be involved in regulating Hox transcription in several tissues but not in the paraxial mesoderm, at least at the stages studied here.

Despite the absence of changes in Hox transcription in the paraxial mesoderm, Meis mutants produce anterior homeotic transformations and defects similar to those 
previously described for Hox mutants involved in patterning the occipital, cervical and thoracic regions (Horan et al., 1995; Jeannotte et al., 1993; Manley and Capecchi, 1997; Mclntyre et al., 2007). This is consistent with studies in flies in which the elimination of the Meis ortholog homothorax produces homeotic phenotypes through modifying Hox protein DNA affinity and target selectivity without altering Hox gene transcription (Merabet and Mann, 2016; Rieckhof et al., 1997).

We deleted Meis2 using different Cre lines that recombine at different stages of epiblast cell recruitment to the paraxial mesoderm, however we did not find any substantial influence of the timing of Meis2 removal on the phenotypes obtained. Using DII1 ${ }^{\mathrm{Cre}}$, which recombines in the pre-somitic mesoderm, the severity of the defects observed increases with the number of Meis alleles deleted, supporting a cooperation between Meis1 and Meis2 in axial patterning. The early expression of Meis2 in the posterior epiblast thus seems not to play any role in axial skeletal patterning, while both Meis1 and Meis2 cooperate at the presomitic mesoderm, or at later stages of somite development, in axial patterning. Although it has been suggested that segmental identity specification occurs in the PSM before somites are formed (Carapuco et al., 2005), we cannot exclude the involvement of Meis during later somite development, given that Meis is also present in the differentiating paraxial mesoderm and that we have not eliminated Meis function specifically from the differentiating somites.

Apart from its function in segmental identity, the transcriptional analysis of the mutants indicates an important function in hypaxial myotome development, with profound alterations of both patterning and myogenic pathways. Interestingly, Myf5, MRF4 and Myogenin-deficient mice show rib defects similar to those described here (Braun et al., 1992; Hasty et al., 1993; Patapoutian et al., 1995), and therefore, the failure in proper activation of the hypaxial myogenic program is sufficient to explain rib mispatterning in Meis1/2 double KOs. Moreover, hypaxial myotomal FGF4 and FGF6 expression, required for rib patterning downstream the myogenic factors (Vinagre et al., 2010), is strongly impaired in Meis mutants, indicating a function of Meis in the cross-talk between myotome and sclerotome. In addition, the activation of the myogenic program involved in rib pattering is under direct control of a specific set of Hox proteins involved in the specification of thoracic segments (Vinagre et al., 2010). The rib mispatterning phenotypes therefore may also partly involve the impairment of Hox function in the absence of Meis.

RNA-seq analysis and in situ hybridization revealed a reduction in Raldh2 and Cyp26b1 in Meis mutants. Since the activation of Cyp26b1 is RA-dependent, its downregulation in Meis mutants could be a secondary event, due to the reduction in RA synthesis by Raldh2. Cyp26b1 mutants show posterior homeotic transformations in the 
occipital/cervical region (Sakai et al., 2001), associated to increased RA levels. The posterior transformations in this model are opposite to those observed in Meis mutants, which concurs with the idea that Meis is a positive regulator of RA synthesis. In addition, in vivo treatments with RA during mouse gestation caused either anterior or posterior homeotic transformations depending on the stage of the treatment (Kessel and Gruss, 1991). In the cervical region, anterior transformations were observed following treatments at $\mathrm{E} 7$ while posterior transformations were found following RA treatment from E8 (Kessel, 1992). On the other hand, Raldh2 knockout mice die around E10.5 from an impairment in RA synthesis (Niederreither et al., 1999), however, a conditional approach that would allow studying the skeletal pattern was missing. We generated a Raldh2 conditional knockout using the DII1 $1^{\text {Cre }}$ driver and found homeotic transformations affecting the occipital/cervical region, and additional patterning defects in the thoracic region that significantly overlap with those observed in Meis mutants. In agreement with this, mutations in RARs lead to homeotic transformations (Lohnes et al., 1993; Lohnes et al., 1994) similar to those observed in Meis mutants. In particular, RARY and RAR loss of function mutants show anterior transformations without showing any changes in Hox expression patterns (Folberg et al., 1999a; Folberg et al., 1999b).

At the molecular level, we described a positive regulatory loop between Meis and RA that we confirmed by functional genetic analysis. The similarities in skeletal transformations between Raldh2 and Meis mutants and the cross-regulation between Raldh2 and Meis suggests that the positive regulatory loop between Raldh2 and Meis is involved in axial patterning. While Meis genes are RA targets in various contexts (Mercader et al., 2000; Oulad-Abdelghani et al., 1997; Yashiro et al., 2004), Raldh2 is a direct Meis target in the hindbrain (Vitobello et al., 2011), and ChIPseq analysis in E10.5 limb buds (Delgado et al., 2020) identifies Meis binding sites in the Raldh2 locus. In fact, Meis could promote RA accumulation at various levels, as it also represses Cyp26b1 during limb development in a cell-autonomous manner (Rosello-Diez et al., 2014). The requirement of Meis activity for Raldh2 transcription in the paraxial mesoderm is restricted to the differentiation stages and does not take place in the nascent or segmenting mesoderm. In coincidence with our findings, $P b \times 1 / 2$ null embryos show normal Raldh2 expression at early embryonic stages but strong downregulation in the paraxial mesoderm at E9.0 and beyond (Rosello-Diez et al., 2014).

Finally, we studied the functional output of the Meis-RA regulatory loop by genetic rescue. The complete rescue of Raldh2 mutants by Meis overexpression suggest that Meis is the main functional output of the positive regulatory loop between Meis and RA in the paraxial mesoderm. 
We propose a model for the RA-Meis-Hox network in the paraxial mesoderm in which Meis is involved in a positive feedback loop with RA through Raldh2 regulation. Meis is the main output of this regulatory loop and is required for the specification of axial skeletal identities, likely through regulating Hox protein activity. The proposed model provides a possible explanation to the ability of RA and RARs to phenocopy Hox mutants without affecting their transcriptional expression.

\section{MATERIALS AND METHODS}

\section{Mouse lines and embryo harvest}

Experiments were performed using mice (Mus musculus). Mice were handled in accordance with CNIC Ethics Committee, Spanish laws and the EU Directive 2010/63/EU for the use of animals in research. All mouse experiments were approved by the CNIC and Universidad Autónoma de Madrid Committees for "Ética y Bienestar Animal" and the area of "Protección Animal" of the Community of Madrid with reference PROEX 220/15.

Meis conditional knockouts were generated mating Meis $1^{\text {flox }}$ (Unnisa et al., 2012) and Meis2 ${ }^{\text {flox }}$ (Delgado et al., 2020) with different Cre lines: Sox ${ }^{\text {Cre }}$ (Hayashi et al., 2002), Mesp $1^{\text {Cre }}$ (Saga et al., 1999), DII1 ${ }^{\text {Cre }}$ (Wehn et al., 2009), Stra $8^{\text {Cre }}$ (Sadate-Ngatchou et al., 2008) and $Z p 3^{C r e}$ (de Vries et al., 2000). Raldh2 conditional knockouts were obtained by mating Raldh2 flox mice (79) to DII1 ${ }^{\text {Cre }}$ and Sox $2^{\text {Cre }}$. For $\mathrm{Cre}^{+}$cell lineage tracing we used $\operatorname{Gt}(R O S A)^{26 S o r t m 14(C A G-t d T o m a t o) H z e}$ (Madisen et al., 2010). For conditional Meis overexpression we used the Rosa26R ${ }^{\text {Meis2-EYFP }}$ line (Rosello-Diez et al., 2014).

To obtain embryos at different gestational stages, mice were mated in the afternoon and females were checked every morning for the presence of a vaginal plug; noon of the day the plug was observed and considered as gestational day 0.5 (E0.5). Embryos at somitogenic stages were staged according to age and somite number. Embryos that had not started somitogenesis were staged according to (Downs and Davies, 1993).

\section{In situ hybridization}

Embryos were fixed in $4 \%$ PFA overnight at $4^{\circ} \mathrm{C}$. Embryos were dehydrated and rehydrated washing them with increasing and decreasing, respectively concentrations of methanol in PBT $(25 \%, 50 \%, 75 \%$ and $100 \%)$. Bleaching was carried out by incubation in $6 \% \mathrm{H}_{2} \mathrm{O}_{2}$ in PBT during one hour. Proteinase $\mathrm{K}$ (Sigma) digestion was performed at $10 \mu \mathrm{g} / \mathrm{ml}$ with different incubation times depending on the stage. After permeabilization, embryos were washed with PBT during 5 minutes and fixed with glutaraldehyde $0.05 \%$ 
in 4\%PFA during 20 minutes. Embryos were incubated in hybridization buffer $(50 \%$ Formamide, 4x SSC pH 4.5, $1 \%$ SDS, $50 \mu \mathrm{g} / \mathrm{ml}$ heparin (Sigma), $10 \mu \mathrm{g} / \mathrm{ml}$ tRNA from baker's yeast (Sigma), 1\% w/v Blocking reagent (Sigma)) during 2 hours and hybridized with the probe overnight at $65^{\circ} \mathrm{C}$. Posthybridization washes were performed with $0.1 \%$ CHAPS w/v (Sigma), 2x SSC pH 5.5, followed by a second round of posthybridization washes with $0.1 \%$ CHAPS w/v, $0.2 x$ SSC during 3 hours at $65^{\circ} \mathrm{C}$. Embryos were incubated overnight at $4^{\circ} \mathrm{C}$ with 1:2000 anti-digoxigenin AP antibody (Roche) in $20 \%$ Goat serum, $1 \%$ Blocking reagent in TBST $(5 \mathrm{mM}$ Tris- $\mathrm{HCl} \mathrm{pH} 7.5,15 \mathrm{mM} \mathrm{NaCl}, 0.1 \%$ Triton X-100 (Sigma)). After several washes in TBST, embryos were washed with $125 \mathrm{mM}$ Tris- $\mathrm{HCl} \mathrm{pH} 9.5,125 \mathrm{mM} \mathrm{NaCl}, 62.5 \mathrm{mM} \mathrm{MgCl}_{2}, 0.5 \%$ Triton X-100 and stained with BMPurple (Roche) at room temperature until the signal was optimal. After the staining, embryos were washed with TBST, fixed in $4 \%$ PFA and stored at $4{ }^{\circ} \mathrm{C}$. Occasionally, after in situ hybridization embryos were gelatin embedded and cryosectioned.

\section{Probe synthesis}

RNA antisense probes were synthesized by transcription of linearized DNA from plasmids or from cDNA amplified with specific primers (S2 Table). Transcription was carried out with digoxigenin labelled nucleotides (Roche) and T7 RNA polymerase (Roche). Synthesized RNA was precipitated with $0.8 \mathrm{M}$ ammonium acetate in $75 \%$ ethanol or $0.1 \mathrm{M} \mathrm{LiCl}$ in $75 \%$ ethanol and finally resuspended in $50 \%$ formamide $-50 \%$ RNase free water.

\section{Victoria Blue staining}

Embryos at E14.5 were eviscerated and fixed in 10\% formaldehyde overnight and then washed in acid alcohol $(3 \% \mathrm{HCl}$ in $70 \%$ ethanol) several times. Embryos were stained during 3 hours with $0.5 \% \mathrm{w} / \mathrm{v}$ Victoria Blue (Sigma) in acid alcohol and after staining embryos were washed in acid alcohol until the embryos were white, then they were washed in $70 \%$ ethanol and $95 \%$ ethanol. Finally, embryos were clarified with increasing concentrations of Methyl salicylate in ethanol (30\%,50\%) and stored in 100\% Methyl salicylate.

\section{Alcian Blue and Alizarin Red staining}

Embryos at E18.5 were eviscerated and the skin and soft tissues were removed as much as possible. Embryos were fixed overnight with 95\% ethanol and after fixation were submerged in Alcian Blue solution (0.03\% w/v Alcian Blue (Sigma), 80\% ethanol, 20\% glacial acetic acid) overnight. Alcian Blue solution was removed and several washes with 
$70 \%$ ethanol were made during the day; incubating the embryos in $95 \%$ ethanol overnight. Once the tissue becomes whiter, embryos were cleared with $1 \% \mathrm{KOH}$ during 3-6 hours depending on the stage and the amount of soft tissue that the embryos have. Once cleared, Alizaren Red solution (0.005\% Alizarin Red (Sigma), 1\% w/v KOH) was added until the bones were stained. Another clarification step with $1 \% \mathrm{KOH}$ could be done if necessary after staining with Alizarin Red solution, if not embryos were transferred to increasing concentrations of glycerol (20\% and $50 \%)$ and finally placed in $100 \%$ glycerol for long term storage.

\section{Immunostaining and imaging}

Embryos were fixed in 2\% PFA, gelatin embedded and cryosectioned. Sections were permeabilized with 0 ' $5 \%$ Triton X-100 in PBS for 20 minutes and blocking was performed with $20 \%$ goat serum in PBS for 1 hour. The primary antibodies used overnight at $4^{\circ}$ were a rabbit anti-Aldh1a2 (ab96060) and an anti-Meisa, recognizing C-terminal short isoform of Meis1 and Meis2 (Mercader et al., 2005). Secondary antibodies were incubated during 45 minutes at room temperature. Secondary antibodies used were an Alexa-488 (1:500) for anti-Meis-a and an anti-HRP (1:200) for anti-Aldh1a2. After antiHRP incubation, amplification with Tyr-FITC (1:100) during 3 minutes at room temperature was performed. Sections were incubated with DAPI and mounted in Vectashield or Dako fluorescent mounting media for acquisition. Images were acquired using a Nikon A1R confocal microscope using 405, 488 and $561 \mathrm{~nm}$ wavelengths and Plan Apo 10x DIC L or Plan Apo VC 20x DIC N2 dry objectives.

\section{mRNA sequencing}

Differential gene expression analysis was carried out between $D I / 1^{\text {Cre }}$;Meis $1^{\text {flox/flox }}$;Meis $2^{\text {flox/flox }}$ and control embryos at E9. Four embryos were used for each condition and were staged by somite number, choosing the embryos with 20-24 somites. Total RNA was isolated using RNeasy Micro Kit (Qiagen) separating the anterior region containing the first 10-12 somites (the head was excluded) and the posterior region with the rest of the somites and the posterior embryonic bud. 20ng of total RNA were used to generate barcoded RNA-seq libraries using the NEBNext Ultra RNA Library preparation kit (New England Biolabs). The size and the concentration of the libraries were checked using the TapeStation 2200 DNA 1000 chip. Libraries were sequenced on a HiSeq2500 (Illumina) to generate 60 bases single reads. FastQ files for each sample were obtained using bcltofastQ software 2.20 .

\section{RNA-seq data analysis}


Sequencing reads were pre-processed by means of a pipeline that used FastQC (http://www.bioinformatics.babraham.ac.uk/projects/fastqc/), to asses read quality, and Cutadapt (Martin, 2011) to trim sequencing reads, eliminating Illumina adaptor remains, and to discard reads that were shorter than $30 \mathrm{bp}$. The resulting reads were mapped against the mouse transcriptome (GRCm38, release 91; dec2017 archive) and quantified using RSEM v1.2.20 (Li and Dewey, 2011). Data were then processed with a pipeline that used Bioconductor package Limma (Ritchie et al., 2015) for normalization and differential expression analysis, using a blocking strategy to consider gender and developmental stage (number of somites). Genes with at least 1 count per million in at least 4 samples $(14,731$ genes) were considered for further analysis. We considered as differentially expressed those genes with Benjamini-Hochberg adjusted $p$ value $<0.05$. Fold change and log(ratio) values were calculated to represent gene expression differences between conditions.

ACKNOWLEDGEMENTS: We thank members of the Torres group for stimulating discussions and suggestions. We thank members of the Genomics, Bioinformatics, Pluripotent Cell Technology, Transgenesis and Animal Facility CNIC units for excellent support. Meis 1 floxed mice were generated by Keith Humphries and kindly provided by Hesham Sadek. We thank Miguel Manzanares for providing mouse strains and Marian Ros, Aimee Zuniga, Paola Bovolenta, Robb Krumlauf and Jose Luis de la Pompa for kindly providing in situ probes. Funding: PGC2018-096486-B-I00 from the Spanish Ministry of Science, Innovation and Universities, RD16/0011/0019 from Instituto de Salud Carlos III and grant S2017/BMD-3875 from the Comunidad de Madrid. The CNIC is supported by the Ministerio de Ciencia, Innovación y Universidades and the Pro CNIC Foundation, and is a Severo Ochoa Center of Excellence (SEV-2015-0505). Author contributions: conceptualization: M.T. and A.C.L.; methodology: A.C.L., I.D. and V.C.; statistics: F.S.; investigation: A.C.L., V.C. and M.T.; writing (original draft): M.T. and A.C.L.; writing (review and editing): M.T., A.C.L.; supervision: M.T.; funding acquisition: M.T. Competing Interests: The authors declare no competing interests. Data and materials availability: All data needed to evaluate the conclusions in the paper are present in the paper and/or the Supplementary Materials except the RNA-seq data, which are available from GEO with reference number GSE146301. Materials are available from authors upon request. 


\section{REFERENCES}

Alexander, T., Nolte, C. and Krumlauf, R. (2009). Hox genes and segmentation of the hindbrain and axial skeleton. Annual review of cell and developmental biology 25, 431-456.

Amin, S., Donaldson, I. J., Zannino, D. A., Hensman, J., Rattray, M., Losa, M., Spitz, F., Ladam, F., Sagerstrom, C. and Bobola, N. (2015). Hoxa2 selectively enhances Meis binding to change a branchial arch ground state. Developmental cell 32, 265-277.

Berenguer, M., Meyer, K. F., Yin, J. and Duester, G. (2020). Discovery of genes required for body axis and limb formation by global identification of retinoic acidregulated epigenetic marks. PLoS Biol 18, e3000719.

Braun, T., Rudnicki, M. A., Arnold, H. H. and Jaenisch, R. (1992). Targeted inactivation of the muscle regulatory gene Myf-5 results in abnormal rib development and perinatal death. Cell 71, 369-382.

Capellini, T. D., Zewdu, R., Di Giacomo, G., Asciutti, S., Kugler, J. E., Di Gregorio, A. and Selleri, L. (2008). Pbx1/Pbx2 govern axial skeletal development by controlling Polycomb and Hox in mesoderm and Pax1/Pax9 in sclerotome. Developmental biology 321, 500-514.

Carapuco, M., Novoa, A., Bobola, N. and Mallo, M. (2005). Hox genes specify vertebral types in the presomitic mesoderm. Genes \& development 19, 21162121.

Chan, S. K., Jaffe, L., Capovilla, M., Botas, J. and Mann, R. S. (1994). The DNA binding specificity of Ultrabithorax is modulated by cooperative interactions with extradenticle, another homeoprotein. Cell 78, 603-615.

Chang, C. P., Brocchieri, L., Shen, W. F., Largman, C. and Cleary, M. L. (1996). $\mathrm{Pbx}$ modulation of Hox homeodomain amino-terminal arms establishes different DNA-binding specificities across the Hox locus. Molecular and cellular biology 16, 1734-1745.

Choe, S. K., Ladam, F. and Sagerstrom, C. G. (2014). TALE factors poise promoters for activation by Hox proteins. Developmental cell 28, 203-211.

de Vries, W. N., Binns, L. T., Fancher, K. S., Dean, J., Moore, R., Kemler, R. and Knowles, B. B. (2000). Expression of Cre recombinase in mouse oocytes: a means to study maternal effect genes. Genesis 26, 110-112.

Delgado, I., López-Delgado, A. C., Roselló-Díez, A., Giovinazzo, G., Cadenas, V., Fernández del Manuel, L., Sánchez-Cabo, F., Anderson, M. J., Lewandoski, M. and Torres, M. (2020). Proximo-distal positional information encoded by an Fgf-regulated gradient of homeodomain transcription factors in the vertebrate limb. Science Advances 6, eaaz0742.

Deschamps, J., de Laaf, R., Joosen, L., Meijlink, F. and Destree, O. (1987). Abundant expression of homeobox genes in mouse embryonal carcinoma cells correlates with chemically induced differentiation. Proceedings of the National Academy of Sciences of the United States of America 84, 1304-1308.

Deschamps, J. and Duboule, D. (2017). Embryonic timing, axial stem cells, chromatin dynamics, and the Hox clock. Genes \& development 31, 1406-1416.

Dibner, C., Elias, S. and Frank, D. (2001). XMeis3 protein activity is required for proper hindbrain patterning in Xenopus laevis embryos. Development (Cambridge, England) 128, 3415-3426.

Downs, K. M. and Davies, T. (1993). Staging of gastrulating mouse embryos by morphological landmarks in the dissecting microscope. Development (Cambridge, England) 118, 1255-1266.

Duboule, D. and Dolle, P. (1989). The structural and functional organization of the murine HOX gene family resembles that of Drosophila homeotic genes. The EMBO journal 8, 1497-1505. 
Folberg, A., Kovacs, E. N., Huang, H., Houle, M., Lohnes, D. and Featherstone, M. S. (1999a). Hoxd4 and Rarg interact synergistically in the specification of the cervical vertebrae. Mechanisms of development 89, 65-74.

Folberg, A., Nagy Kovacs, E., Luo, J., Giguere, V. and Featherstone, M. S. (1999b). RARbeta mediates the response of Hoxd4 and Hoxb4 to exogenous retinoic acid. Dev Dyn 215, 96-107.

Gaunt, S. J., Miller, J. R., Powell, D. J. and Duboule, D. (1986). Homoeobox gene expression in mouse embryos varies with position by the primitive streak stage. Nature 324, 662-664.

Grass, S., Arnold, H. H. and Braun, T. (1996). Alterations in somite patterning of Myf5-deficient mice: a possible role for FGF-4 and FGF-6. Development (Cambridge, England) 122, 141-150.

Grifone, R., Demignon, J., Giordani, J., Niro, C., Souil, E., Bertin, F., Laclef, C., Xu, P. X. and Maire, P. (2007). Eya1 and Eya2 proteins are required for hypaxial somitic myogenesis in the mouse embryo. Developmental biology 302, 602616.

Hasty, P., Bradley, A., Morris, J. H., Edmondson, D. G., Venuti, J. M., Olson, E. N. and Klein, W. H. (1993). Muscle deficiency and neonatal death in mice with a targeted mutation in the myogenin gene. Nature 364, 501-506.

Hayashi, S., Lewis, P., Pevny, L. and McMahon, A. P. (2002). Efficient gene modulation in mouse epiblast using a Sox2Cre transgenic mouse strain. Mechanisms of development 119 Suppl 1, S97-S101.

Horan, G. S., Ramirez-Solis, R., Featherstone, M. S., Wolgemuth, D. J., Bradley, A. and Behringer, R. R. (1995). Compound mutants for the paralogous hoxa-4, hoxb-4, and hoxd-4 genes show more complete homeotic transformations and a dose-dependent increase in the number of vertebrae transformed. Genes \& development 9, 1667-1677.

Huang, R., Lang, E. R., Otto, W. R., Christ, B. and Patel, K. (2001). Molecular and cellular analysis of embryonic avian tongue development. Anatomy and embryology 204, 179-187.

Ikeya, M. and Takada, S. (1998). Wnt signaling from the dorsal neural tube is required for the formation of the medial dermomyotome. Development (Cambridge, England) 125, 4969-4976.

Jeannotte, L., Lemieux, M., Charron, J., Poirier, F. and Robertson, E. J. (1993). Specification of axial identity in the mouse: role of the Hoxa-5 (Hox1.3) gene. Genes \& development 7, 2085-2096.

Kessel, M. (1992). Respecification of vertebral identities by retinoic acid. Development (Cambridge, England) 115, 487-501.

Kessel, M. and Gruss, P. (1991). Homeotic transformations of murine vertebrae and concomitant alteration of Hox codes induced by retinoic acid. Cell 67, 89-104.

Krumlauf, R. (1994). Hox genes in vertebrate development. Cell 78, 191-201.

Lewis, E. B. (1978). A gene complex controlling segmentation in Drosophila. Nature 276, 565-570.

Li, B. and Dewey, C. N. (2011). RSEM: accurate transcript quantification from RNASeq data with or without a reference genome. BMC bioinformatics 12, 323.

Lohnes, D., Kastner, P., Dierich, A., Mark, M., LeMeur, M. and Chambon, P. (1993). Function of retinoic acid receptor gamma in the mouse. Cell 73, 643-658.

Lohnes, D., Mark, M., Mendelsohn, C., Dolle, P., Dierich, A., Gorry, P., Gansmuller, A. and Chambon, P. (1994). Function of the retinoic acid receptors (RARs) during development (I). Craniofacial and skeletal abnormalities in RAR double mutants. Development (Cambridge, England) 120, 2723-2748.

Madisen, L., Zwingman, T. A., Sunkin, S. M., Oh, S. W., Zariwala, H. A., Gu, H., Ng, L. L., Palmiter, R. D., Hawrylycz, M. J., Jones, A. R., et al. (2010). A robust 
and high-throughput Cre reporting and characterization system for the whole mouse brain. Nat Neurosci 13, 133-140.

Manley, N. R. and Capecchi, M. R. (1997). Hox group 3 paralogous genes act synergistically in the formation of somitic and neural crest-derived structures. Developmental biology 192, 274-288.

Mann, R. S. and Affolter, M. (1998). Hox proteins meet more partners. Current opinion in genetics \& development 8, 423-429.

Marshall, H., Morrison, A., Studer, M., Popperl, H. and Krumlauf, R. (1996). Retinoids and Hox genes. Faseb J 10, 969-978.

Martin, M. (2011). Cutadapt removes adapter sequences from high-throughput sequencing reads. EMBnetjournal, North America 17, 10-12.

McGinnis, W., Levine, M. S., Hafen, E., Kuroiwa, A. and Gehring, W. J. (1984). A conserved DNA sequence in homoeotic genes of the Drosophila Antennapedia and bithorax complexes. Nature 308, 428-433.

McIntyre, D. C., Rakshit, S., Yallowitz, A. R., Loken, L., Jeannotte, L., Capecchi, M. R. and Wellik, D. M. (2007). Hox patterning of the vertebrate rib cage. Development (Cambridge, England) 134, 2981-2989.

Merabet, S. and Mann, R. S. (2016). To Be Specific or Not: The Critical Relationship Between Hox And TALE Proteins. Trends Genet 32, 334-347.

Mercader, N., Leonardo, E., Azpiazu, N., Serrano, A., Morata, G., Martinez, C. and Torres, M. (1999). Conserved regulation of proximodistal limb axis development by Meis1/Hth. Nature 402, 425-429.

Mercader, N., Leonardo, E., Piedra, M. E., Martinez, A. C., Ros, M. A. and Torres, M. (2000). Opposing RA and FGF signals control proximodistal vertebrate limb development through regulation of Meis genes. Development (Cambridge, England) 127, 3961-3970.

Mercader, N., Selleri, L., Criado, L. M., Pallares, P., Parras, C., Cleary, M. L. and Torres, M. (2009). Ectopic Meis1 expression in the mouse limb bud alters P-D patterning in a Pbx1-independent manner. The International journal of developmental biology 53, 1483-1494.

Mercader, N., Tanaka, E. M. and Torres, M. (2005). Proximodistal identity during vertebrate limb regeneration is regulated by Meis homeodomain proteins. Development (Cambridge, England) 132, 4131-4142.

Muller, F. and O'Rahilly, R. (1994). Occipitocervical segmentation in staged human embryos. Journal of anatomy 185 ( Pt 2), 251-258.

Musumeci, G., Castrogiovanni, P., Coleman, R., Szychlinska, M. A., Salvatorelli, L., Parenti, R., Magro, G. and Imbesi, R. (2015). Somitogenesis: From somite to skeletal muscle. Acta Histochem 117, 313-328.

Nagano, T., Takehara, S., Takahashi, M., Aizawa, S. and Yamamoto, A. (2006). Shisa2 promotes the maturation of somitic precursors and transition to the segmental fate in Xenopus embryos. Development (Cambridge, England) 133, 4643-4654.

Niederreither, K., Subbarayan, V., Dolle, P. and Chambon, P. (1999). Embryonic retinoic acid synthesis is essential for early mouse post-implantation development. Nature genetics 21, 444-448.

Oulad-Abdelghani, M., Chazaud, C., Bouillet, P., Sapin, V., Chambon, P. and Dollé, P. (1997). Meis2, a novel mouse Pbx-related homeobox gene induced by retinoic acid during differentiation of P19 embryonal carcinoma cells. Dev Dyn 210, 173-183.

Patapoutian, A., Yoon, J. K., Miner, J. H., Wang, S., Stark, K. and Wold, B. (1995). Disruption of the mouse MRF4 gene identifies multiple waves of myogenesis in the myotome. Development (Cambridge, England) 121, 3347-3358.

Penkov, D., Mateos San Martin, D., Fernandez-Diaz, L. C., Rossello, C. A., Torroja, C., Sanchez-Cabo, F., Warnatz, H. J., Sultan, M., Yaspo, M. L., Gabrieli, A., et al. (2013). Analysis of the DNA-binding profile and function of TALE 
homeoproteins reveals their specialization and specific interactions with Hox genes/proteins. Cell reports 3, 1321-1333.

Popperl, H., Rikhof, H., Chang, H., Haffter, P., Kimmel, C. B. and Moens, C. B. (2000). lazarus is a novel pbx gene that globally mediates hox gene function in zebrafish. Molecular cell 6, 255-267.

Rhinn, M. and Dolle, P. (2012). Retinoic acid signalling during development. Development (Cambridge, England) 139, 843-858.

Rieckhof, G. E., Casares, F., Ryoo, H. D., Abu-Shaar, M. and Mann, R. S. (1997). Nuclear translocation of extradenticle requires homothorax, which encodes an extradenticle-related homeodomain protein. Cell 91, 171-183.

Ritchie, M. E., Phipson, B., Wu, D., Hu, Y., Law, C. W., Shi, W. and Smyth, G. K. (2015). limma powers differential expression analyses for RNA-sequencing and microarray studies. Nucleic acids research 43, e47.

Rosello-Diez, A., Arques, C. G., Delgado, I., Giovinazzo, G. and Torres, M. (2014). Diffusible signals and epigenetic timing cooperate in late proximo-distal limb patterning. Development (Cambridge, England) 141, 1534-1543.

Sadate-Ngatchou, P. I., Payne, C. J., Dearth, A. T. and Braun, R. E. (2008). Cre recombinase activity specific to postnatal, premeiotic male germ cells in transgenic mice. Genesis 46, 738-742.

Saga, Y., Miyagawa-Tomita, S., Takagi, A., Kitajima, S., Miyazaki, J. and Inoue, T. (1999). MesP1 is expressed in the heart precursor cells and required for the formation of a single heart tube. Development (Cambridge, England) 126, 34373447.

Sakai, Y., Meno, C., Fujii, H., Nishino, J., Shiratori, H., Saijoh, Y., Rossant, J. and Hamada, H. (2001). The retinoic acid-inactivating enzyme CYP26 is essential for establishing an uneven distribution of retinoic acid along the anterioposterior axis within the mouse embryo. Genes \& development 15, 213-225.

Sanchez-Herrero, E., Vernos, I., Marco, R. and Morata, G. (1985). Genetic organization of Drosophila bithorax complex. Nature 313, 108-113.

Selleri, L., Depew, M. J., Jacobs, Y., Chanda, S. K., Tsang, K. Y., Cheah, K. S., Rubenstein, J. L., O'Gorman, S. and Cleary, M. L. (2001). Requirement for $\mathrm{Pbx} 1$ in skeletal patterning and programming chondrocyte proliferation and differentiation. Development (Cambridge, England) 128, 3543-3557.

Shen, W. F., Montgomery, J. C., Rozenfeld, S., Moskow, J. J., Lawrence, H. J., Buchberg, A. M. and Largman, C. (1997). AbdB-like Hox proteins stabilize DNA binding by the Meis1 homeodomain proteins. Molecular and cellular biology 17, 6448-6458.

Tremblay, P., Dietrich, S., Mericskay, M., Schubert, F. R., Li, Z. and Paulin, D. (1998). A crucial role for Pax3 in the development of the hypaxial musculature and the long-range migration of muscle precursors. Developmental biology 203, 49-61.

Unnisa, Z., Clark, J. P., Roychoudhury, J., Thomas, E., Tessarollo, L., Copeland, N. G., Jenkins, N. A., Grimes, H. L. and Kumar, A. R. (2012). Meis1 preserves hematopoietic stem cells in mice by limiting oxidative stress. Blood 120, 4973-4981.

Vinagre, T., Moncaut, N., Carapuco, M., Novoa, A., Bom, J. and Mallo, M. (2010). Evidence for a myotomal Hox/Myf cascade governing nonautonomous control of rib specification within global vertebral domains. Developmental cell 18, 655661.

Vitobello, A., Ferretti, E., Lampe, X., Vilain, N., Ducret, S., Ori, M., Spetz, J. F., Selleri, L. and Rijli, F. M. (2011). Hox and Pbx factors control retinoic acid synthesis during hindbrain segmentation. Developmental cell 20, 469-482.

Vivian, J. L., Olson, E. N. and Klein, W. H. (2000). Thoracic skeletal defects in myogenin- and MRF4-deficient mice correlate with early defects in myotome and intercostal musculature. Developmental biology 224, 29-41. 
Vlachakis, N., Choe, S. K. and Sagerstrom, C. G. (2001). Meis3 synergizes with $\mathrm{Pbx} 4$ and Hoxb1b in promoting hindbrain fates in the zebrafish. Development (Cambridge, England) 128, 1299-1312.

Waskiewicz, A. J., Rikhof, H. A., Hernandez, R. E. and Moens, C. B. (2001). Zebrafish Meis functions to stabilize Pbx proteins and regulate hindbrain patterning. Development (Cambridge, England) 128, 4139-4151.

Wehn, A. K., Gallo, P. H. and Chapman, D. L. (2009). Generation of transgenic mice expressing Cre recombinase under the control of the Dll1 mesoderm enhancer element. Genesis 47, 309-313.

Yashiro, K., Zhao, X., Uehara, M., Yamashita, K., Nishijima, M., Nishino, J., Saijoh, Y., Sakai, Y. and Hamada, H. (2004). Regulation of retinoic acid distribution is required for proximodistal patterning and outgrowth of the developing mouse limb. Developmental cell 6, 411-422.

Zhang, W., Behringer, R. R. and Olson, E. N. (1995). Inactivation of the myogenic bHLH gene MRF4 results in up-regulation of myogenin and rib anomalies. Genes \& development 9, 1388-1399. 


\section{FIGURES}
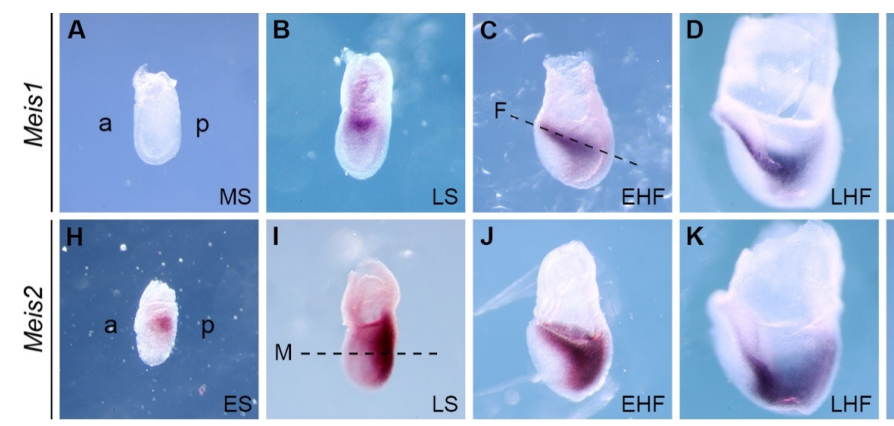
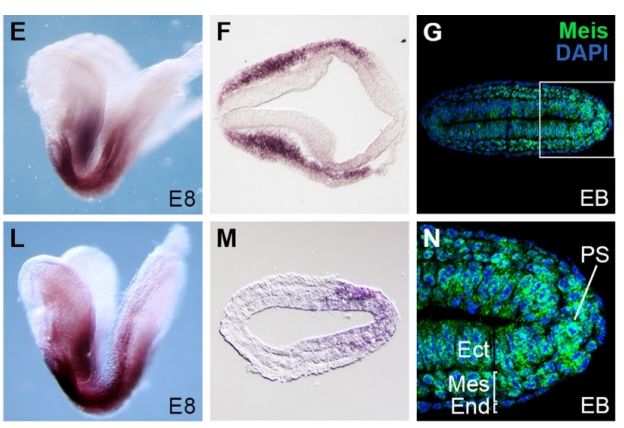

Figure 1. Meis expression pattern in early mouse embryo development.

Whole-mount mRNA in situ hybridization of Meis1 (A-E) and Meis2 (H-L) from E7 to E8. ( $\mathrm{F}$ and $\mathrm{M})$ Transverse sections showing in situ hybridization for Meis1 and Meis2 mRNA, respectively. The approximate plane of the section is indicated by dashed lines in $\mathrm{C}$ and I. (G) Immunostaining with an antibody that recognized both Meis1 and Meis2 on longitudinal sections of an EB embryo across the PS. (N) Magnification of the region marked in $G$ with the three germ layers indicated. a, anterior; $p$, posterior; MS, midstreak; LS, late-streak; EHF, early headfold; LHF, late headfold; ES, early-streak; EB, early allantoic bud; PS, primitive streak; Ect, ectoderm; Mes, mesoderm; End, endoderm. All images are oriented with the anterior to the left and posterior to the right. 


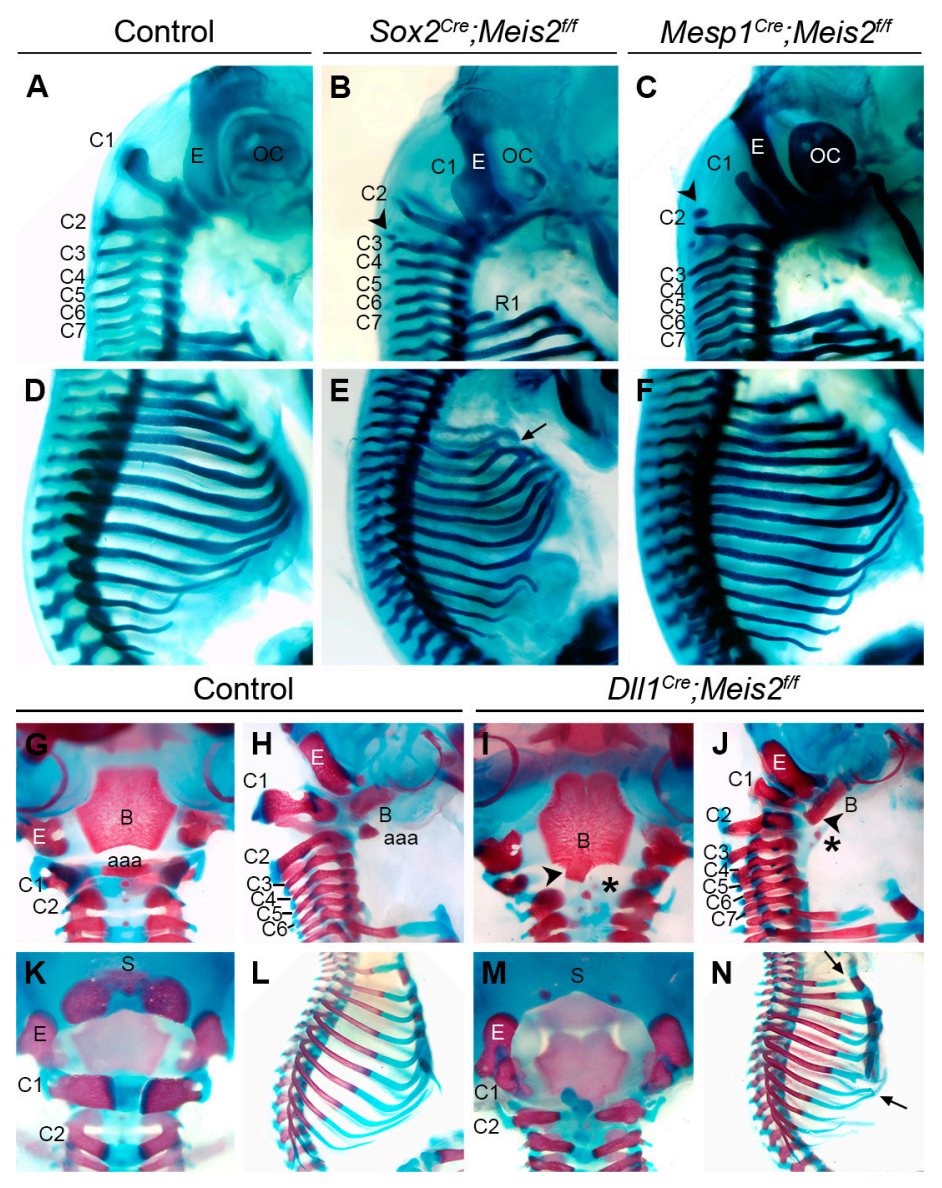

Figure 2. Skeletal defects in conditional Meis2 mutant fetuses using different Cre alleles

(A-F) Victoria blue-stained skeletal preparations of E14.5 fetuses. The cervical region is shown for control $(\mathrm{A})$, Sox $2^{\mathrm{Cre}} ;$ Meis $2^{\mathrm{fff}}(\mathrm{B})$ and Mesp $1^{\text {Cre }} ;$ Meis $2^{\mathrm{fff}}(\mathrm{C})$ fetuses. Arrowheads in $\mathrm{B}$ and $\mathrm{C}$ point to disconnected chondrogenic condensations. The thoracic region is shown for control (D), Sox2 ${ }^{\mathrm{Cre}} ;$ Meis2 $2^{\mathrm{fff}}(\mathrm{E})$ and Mesp $1^{\text {Cre }} ;$ Meis2 ${ }^{\mathrm{fff}}(\mathrm{F})$ fetuses. Arrows in $\mathrm{E}$ and $\mathrm{N}$ point to rib defects. (G-N) alizarin red/alcian blue-stained skeletal preparations of E18 control (G, H; K and L) and DII1 ${ }^{\text {Cre }} ;$ Meis $^{f / f}(\mathrm{I}, \mathrm{J}, \mathrm{M}$ and $\mathrm{N}$ ) fetuses. The occipital region is shown in ventral ( $G$ and $I)$, lateral $(H$ and $J$ ) and dorsal $(K$ and $M$ ) views. ( $L$ and $\mathrm{N})$ lateral views of the thoracic region. Arrowheads in I and $\mathrm{J}$ indicate fusion between the basioccipital and the aaa. Asterisks in I and $\mathrm{J}$ indicate ectopic aaa formed on $\mathrm{C} 2$. aaa, anterior arch of the atlas; B, basioccipital; C, cervical vertebra; E, exoccipital; OC, otic capsule; R, rib; S, supraoccipital. 


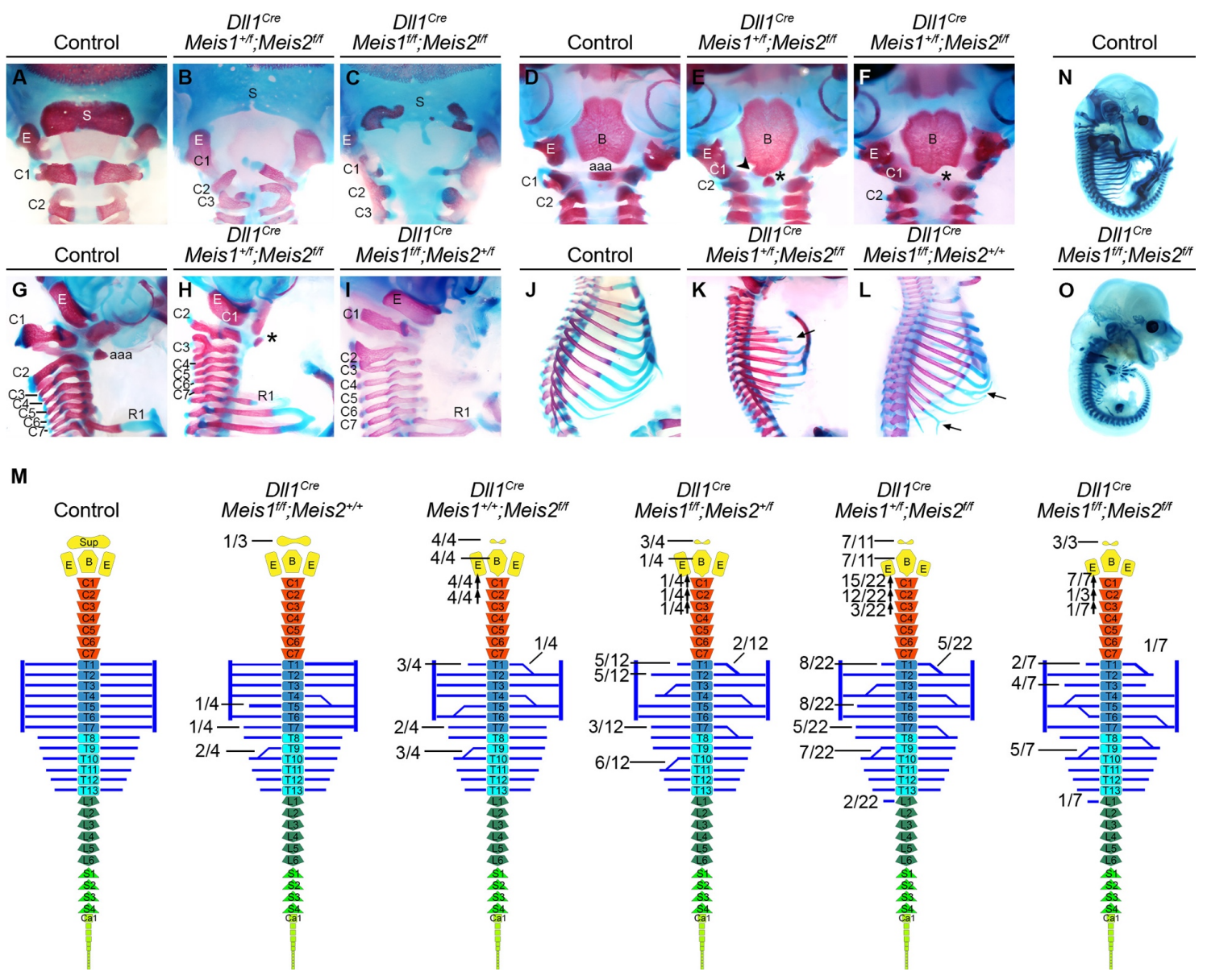

Figure 3. Skeletal defects in Meis1 and Meis2 loss of function mice using DII1

(A-L) alizarin red/alcian blue-stained skeletal preparations of E18.5 fetuses, control or mutant for different combinations of Meis1 and Meis2 floxed alleles and DII1 ${ }^{\text {Cre }}$, as indicated. The occipital region of control and mutant combinations is shown in dorsal (A$C)$, ventral (D-F) and lateral (G-I) views. (J-L) lateral views of the thoracic region. The arrowhead in $\mathrm{E}$ indicates a fusion between the basioccipital and aaa. Asterisks indicate ectopic aaa formed on C2. Arrows in $K$ and $L$ indicate rib defects. (M) Schematic representation of the axial skeleton defects of the different genotypes analyzed and their frequencies. Arrows pointing up indicate apparent anterior homeotic transformations. $(\mathrm{N}$ and O) Victoria blue-stained skeletal preparations of control and DII1 ${ }^{\mathrm{Cre}}$-recombined Meis1/2 homozygous floxed E14.5 fetuses. aaa, anterior arch of the atlas; $\mathrm{B}$, basioccipital; C, cervical vertebra; E, exoccipital; $R$, rib; S, supraoccipital. 
A
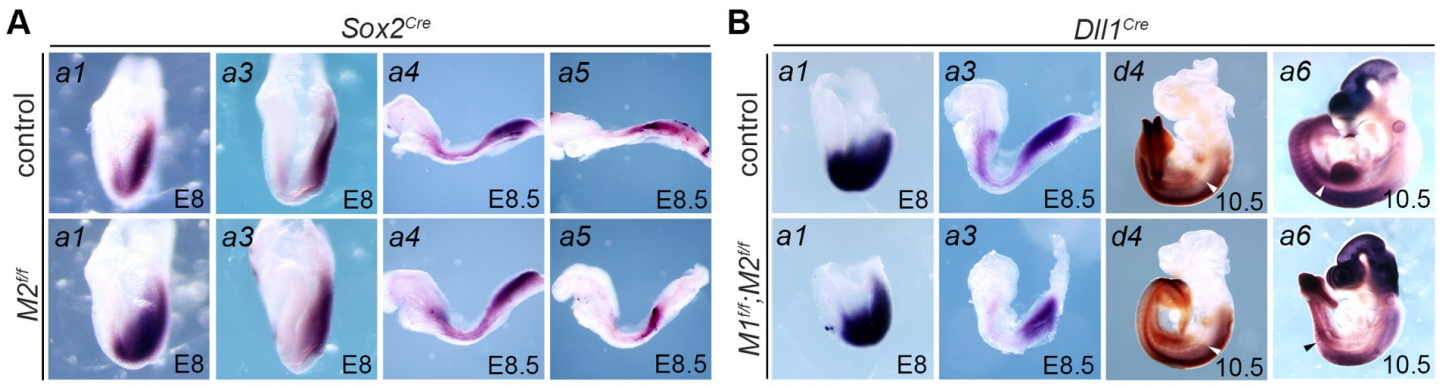

C
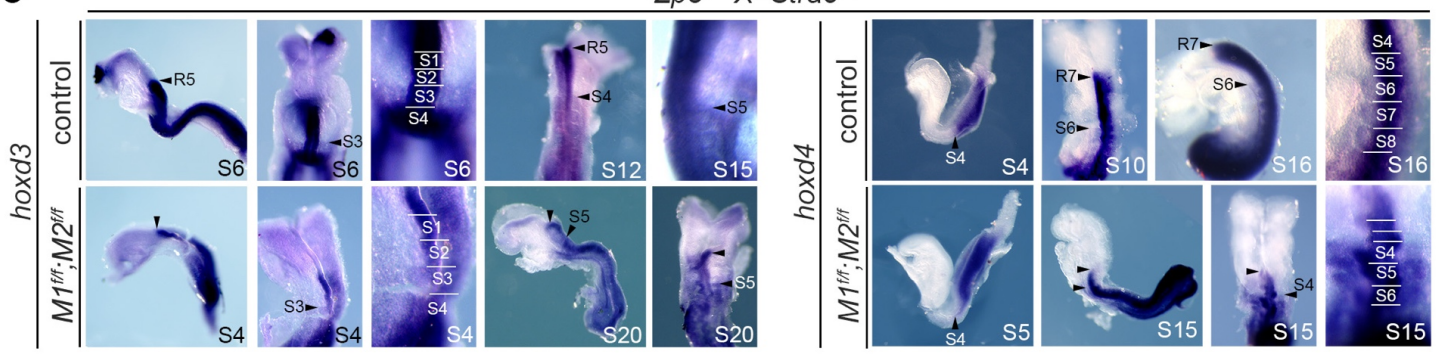

Figure 4. Hox gene mRNA expression patterns in Meis loss-of-function mutants (A) mRNA in situ hybridization of the indicated Hox genes in E8-E8.5 control and Sox2 ${ }^{\text {Cre }}$ recombined Meis2 conditional mutant embryos. (B) mRNA in situ hybridization of the indicated Hox genes in E8-E10.5 control and DII1 ${ }^{\text {Cre }}$-recombined Meis1 and Meis2 conditional mutant embryos. (C) mRNA in situ hybridization of the indicated Hox genes in control and double-floxed Meis1 and Meis2 embryos derived from Zp3 ${ }^{\text {Cre }}$ mothers and Stra8 ${ }^{\text {Cre }}$ fathers. 

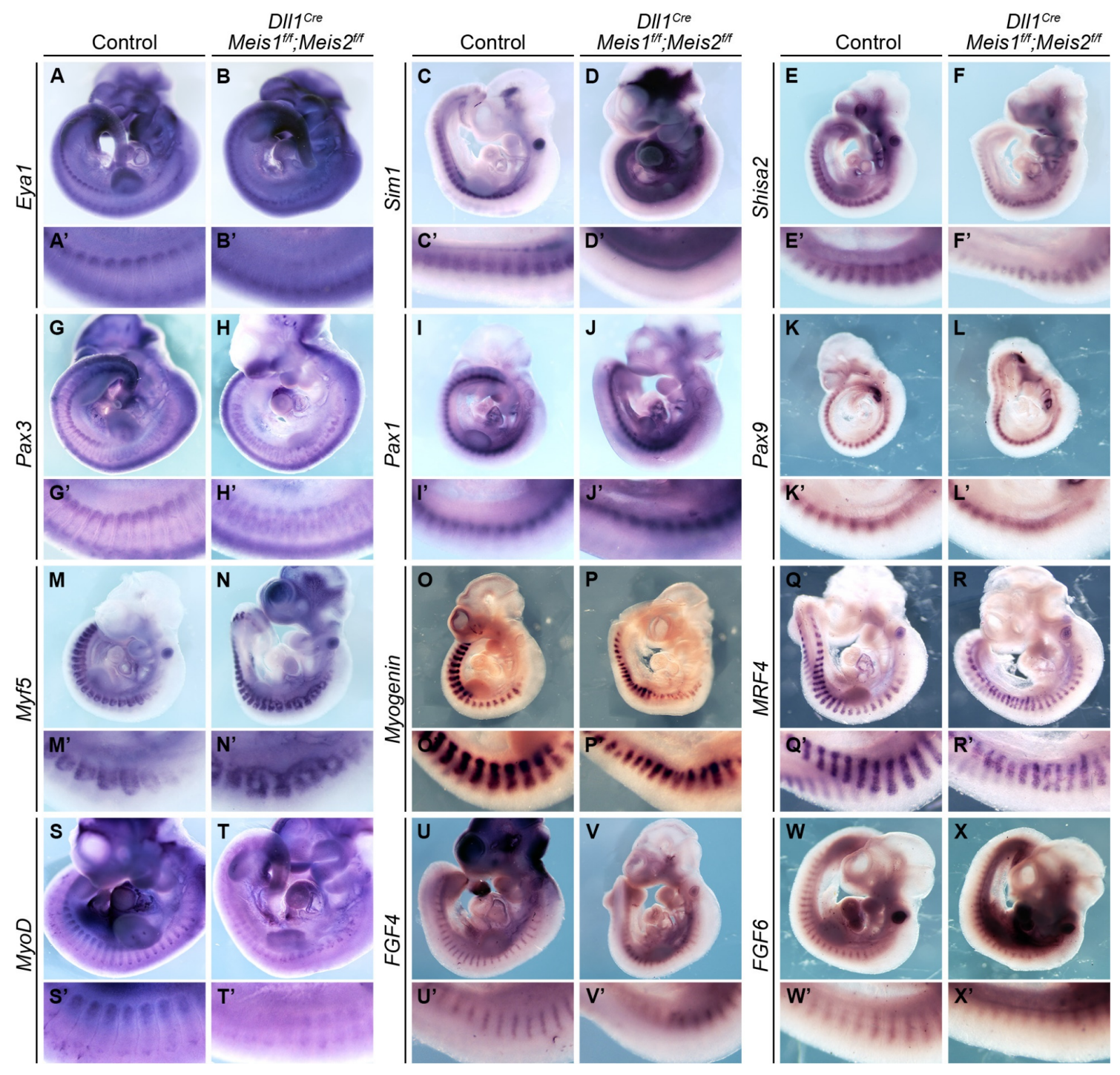

Figure 5. Expression analysis of genes involved in somite development in Meis mutants

Images show whole mount in situ mRNA hybridization in E10.5 embryos showing the expression of genes relevant for somitogenesis in control and DIl1 $1^{\mathrm{Cre}} ; \mathrm{Meis}^{\mathrm{ftf}} ; \mathrm{Meis}^{\mathrm{fff}}$ embryos, as indicated. (A and B) Eya1, (C and D) Sim1, (E and F) Shisa2, (G and H) Pax3, (I and J) Pax1, (K and L) Pax9, (M and N) Myf5, (O and P) Myogenin, (Q and R) MRF4, (S and T) MyoD, ( $\mathrm{U}$ and V) FGF4 and (W and X) FGF6. (A'-X') Magnification of the trunk region of the corresponding image. 

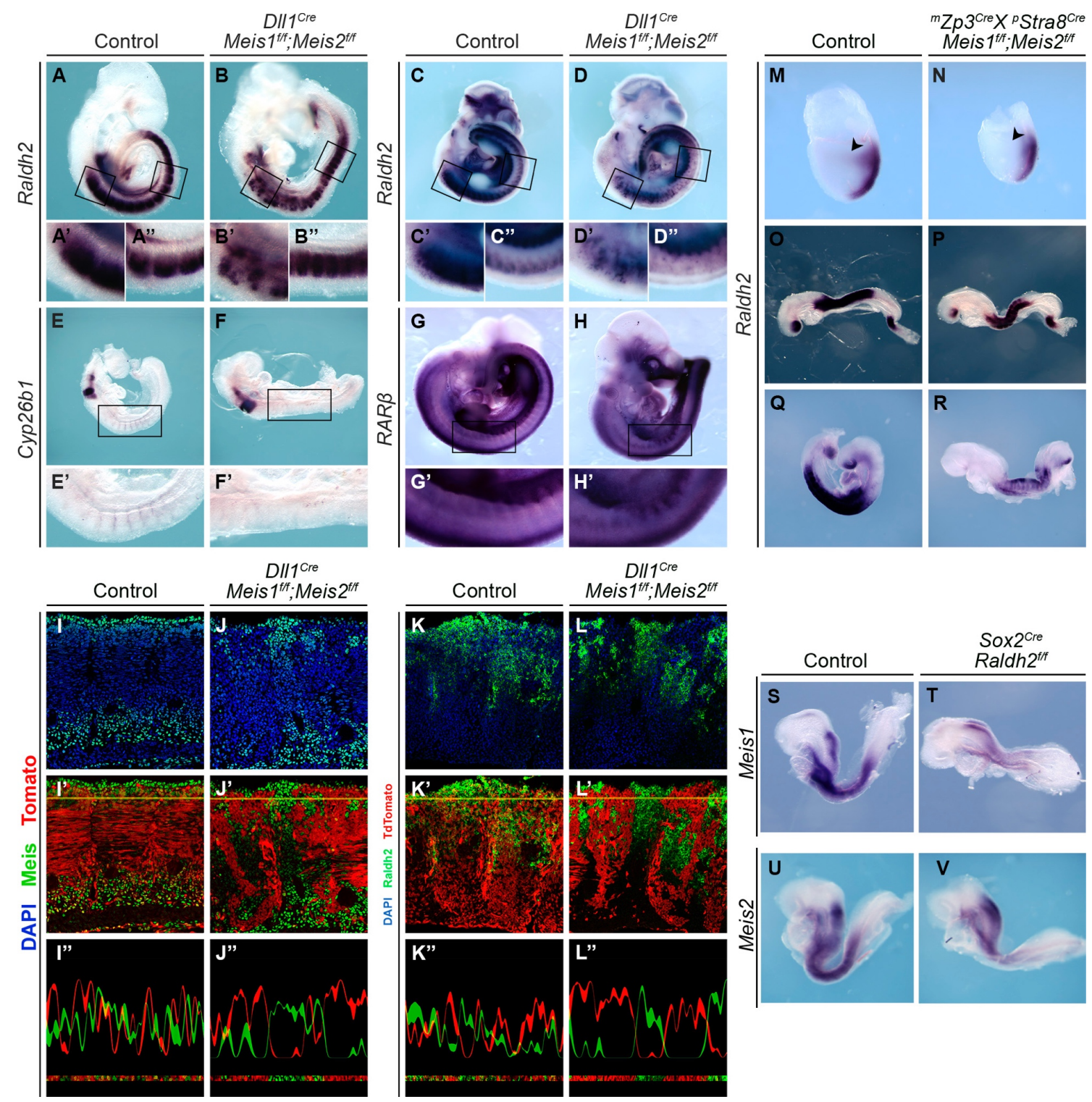

Figure 6. Cross-regulatory interactions between Meis and the Retinoic Acid pathway

(A-D") Raldh2 mRNA in situ hybridization in E9.5 (A-B") and E10.5 (C-D") control and DII ${ }^{\text {Cre }}$-recombined double Meis1 and Meis2 mutant embryos, as indicated. E9.5. (E-F') Cyp26b1 mRNA in situ hybridization of control and DIl1 ${ }^{\text {Cre }}$;Meis ${ }^{1 / f} ;$ Meis $2^{\mathrm{fff}} \mathrm{E} 9$ embryos, as indicated. (G-H') RAR mRNA in situ hybridization of control and $D I I 1^{\text {Cre }}$;Meis $1^{\text {ffff }}$;Meis $2^{f / f}$ E10.5 embryos, as indicated. (A'-H' and A"-D") Magnification of the regions marked in the upper images. (I-L") DII1 ${ }^{\text {Cre }}$ recombination pattern reported by a Rosa26R ${ }^{\text {tdTomato }}$ allele in the anterior somites of E10.5 embryos. Meis and Raldh2 immunofluorescence (I-L') and corresponding quantification plots (I"-L") along the indicated yellow lines in l'-L', in control and DII1 ${ }^{\text {Cre }} ; M e i s 1^{f / f} ; M e i s 2^{f / f}$ embryos, as indicated. (M-R) Raldh2 mRNA in situ hybridization in embryos at E7.5 (M, N), E8.75 (O-P) and E9 $(\mathrm{Q}-\mathrm{R})$ of control $(\mathrm{M}, \mathrm{O}$ and $\mathrm{Q})$ and maternally and paternally-recombined Meis $1^{\mathrm{fff}} ;$ Meis $^{\mathrm{f} / \mathrm{f}}$ $(\mathrm{N}, \mathrm{P}$ and $\mathrm{R}$ ) embryos. Arrowheads indicate the Raldh2 expression domain in the lateral plate in $\mathrm{M}$ and its absence in N. (S-V) Meis1 and Meis2 mRNA in situ hybridization in control (S, U) and Sox $2^{\mathrm{Cre}} ; \mathrm{Raldh}{ }^{f / f}(\mathrm{~T}, \mathrm{~V})$ E8.5 embryos. ${ }^{\mathrm{m}} \mathrm{Zp} 3^{\mathrm{Cre}}$ indicates maternal presence of the allele and ${ }^{p}$ Stra $8^{C r e}$ indicates paternal presence of the allele. 


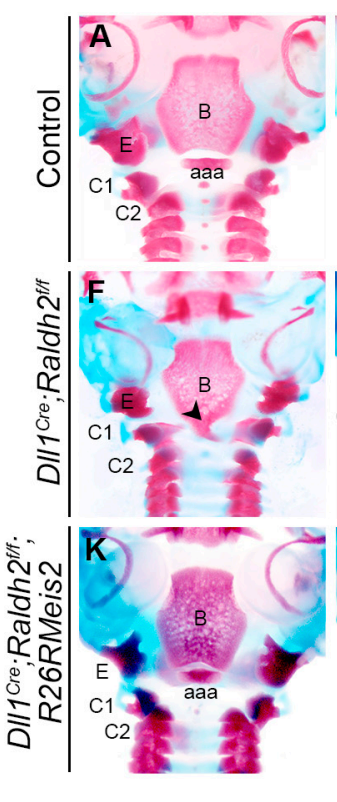

$\mathbf{P}$

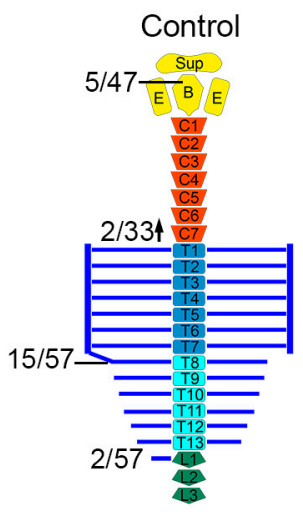

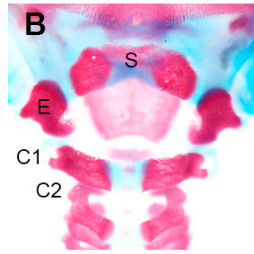
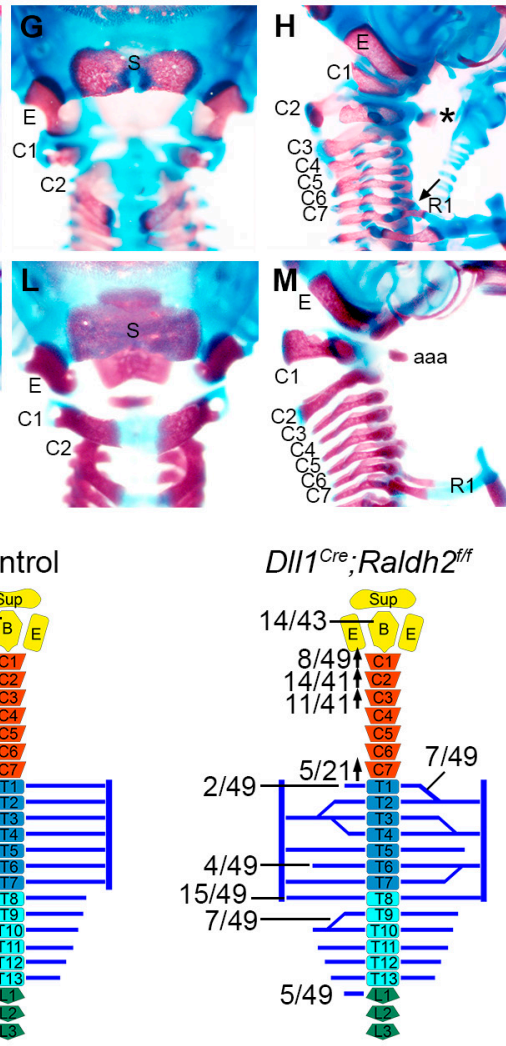
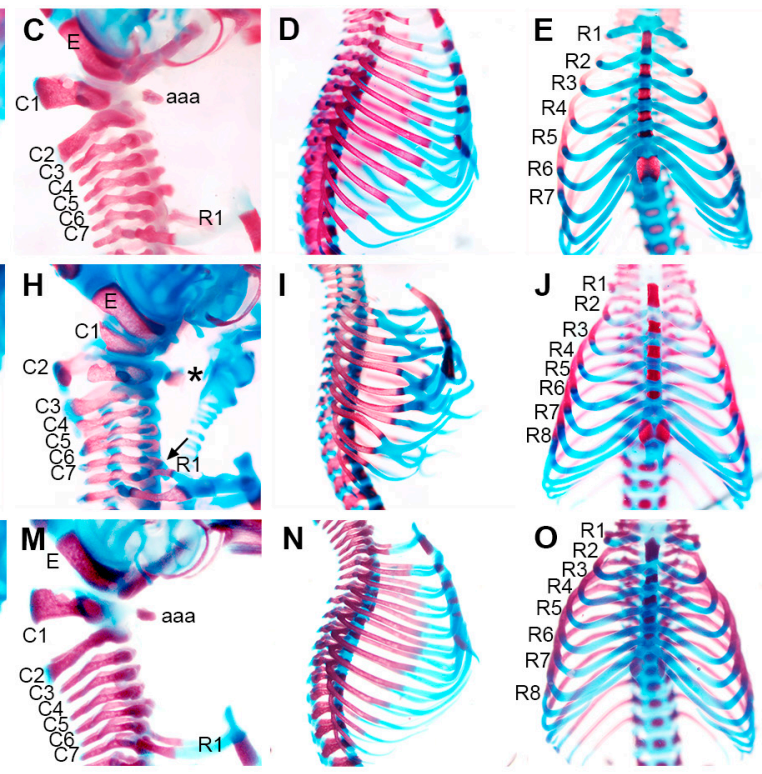

DII ${ }^{\text {Cre }} ;$ Raldh $2^{\text {tf }} ;$ R26RMeis2

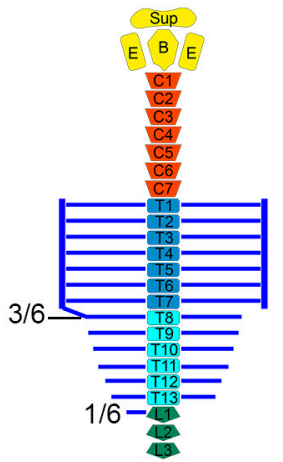

Figure 7. Skeletal defects in $D I I 1^{C r e} ; R a l d h 2^{f / f}$ fetuses and their rescue by Meis2 expression.

(A-J) Skeletal staining of E18.5 fetuses. Ventral view of the basioccipital in control (A) and $D / l 1^{\text {Cre }} ;$ Raldh $2^{f / f}$ fetuses $(F)$. Arrowhead in $\mathrm{F}$ points fusion between basioccipital and aaa. Dorsal view of the supraoccipital in control $(\mathrm{B})$ and $D I / 1^{\mathrm{Cre}} ;$ Raldh2 $2^{\mathrm{ff}}$ fetuses (G). Cervical region in control $(\mathrm{C})$ and $D / l 1^{\text {Cre }} ;$ Raldh2 ${ }^{f / f}$ fetuses $(\mathrm{H})$. Asterisk in $\mathrm{H}$ indicate aaa formed by $\mathrm{C} 2$ and arrow point to tuberculi anterior in $\mathrm{C} 7$. Thoracic region in control (D) and $D / 11^{C r e}$;Raldh2 $2^{f / f}$ fetuses (I). Ventral view of the sternum in control (E) and $D I I 1^{\text {Cre }}$;Raldh2 $2^{f / f}$ fetuses $(\mathrm{J})$. (K) Schematic representation of the axial skeletal defects of $D / l 1^{C r e} ;$ Raldh2 $2^{f / f}$ fetuses and their frequencies. Upward and downward arrows respectively indicate anterior or posterior homeotic transformations. aaa, anterior arch of the atlas; B, basioccipital; C, cervical vertebra; E, exoccipital; R, rib; S, supraoccipital. 


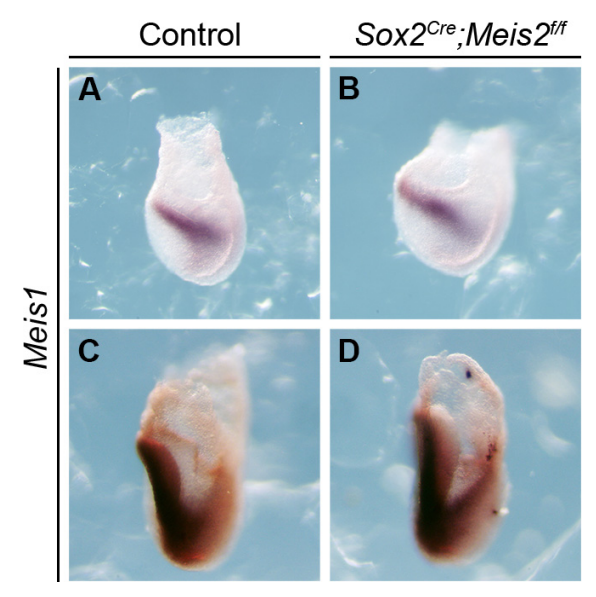

Figure S1. Meis1 mRNA in situ hybridization in control and Sox $2^{\text {Cre }} ;$ Meis $2^{\text {f/f }}$ embryos.

(A and C) Control embryos at E7.5 and E8, respectively. (B and D) Sox2 ${ }^{\text {Cre }} ;$ Meis ${ }^{f / f}$ embryos at E7.5 and E8, respectively.

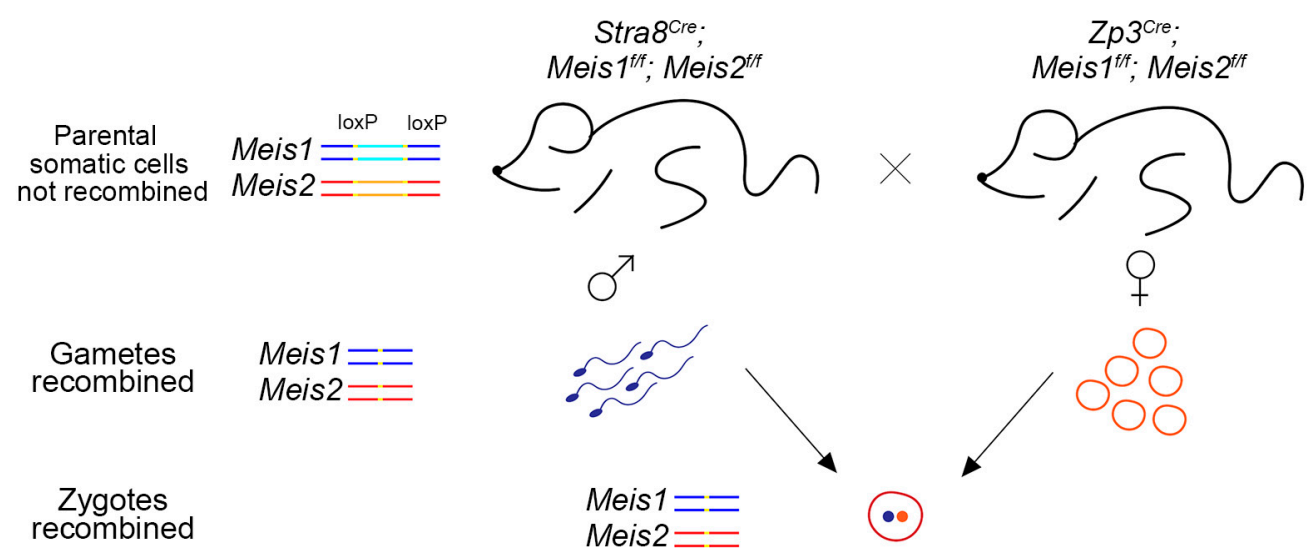

Figure S2. Schematic representation of crosses using biparental germ line Cre recombination to obtain complete zygotic elimination of Meis1 and Meis2. Meis $1^{f / f} ;$ Meis $2^{f / f}$ males and females respectively carrying Stra $8^{\mathrm{Cre}}$ and $\mathrm{Zp} 3^{\mathrm{Cre}}$ alleles only recombine floxed alleles in the germ line. Parental mice are viable while their progeny is double-knockout from the zygotic stage. 


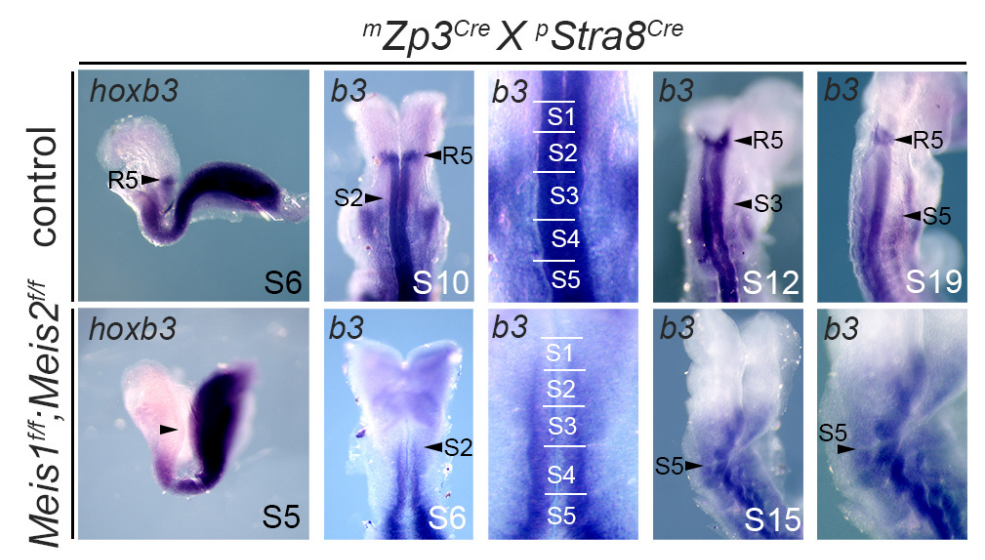

Figure S3. hoxb3 gene mRNA expression patterns in Meis loss-of-function mutants

mRNA in situ hybridization of the indicated Hox genes in control and double-floxed Meis1 and Meis2 embryos derived from $Z p 3^{\text {Cre }}$ mothers and Stra $8^{\text {Cre }}$ fathers. 
A
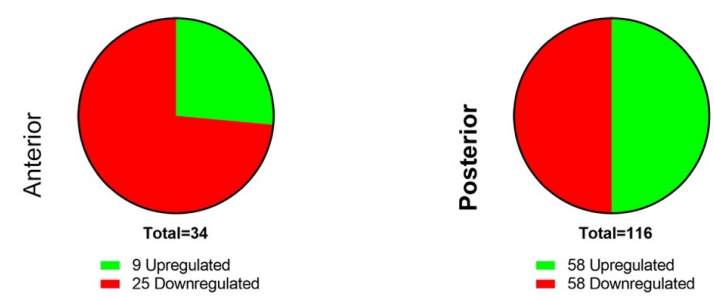

B
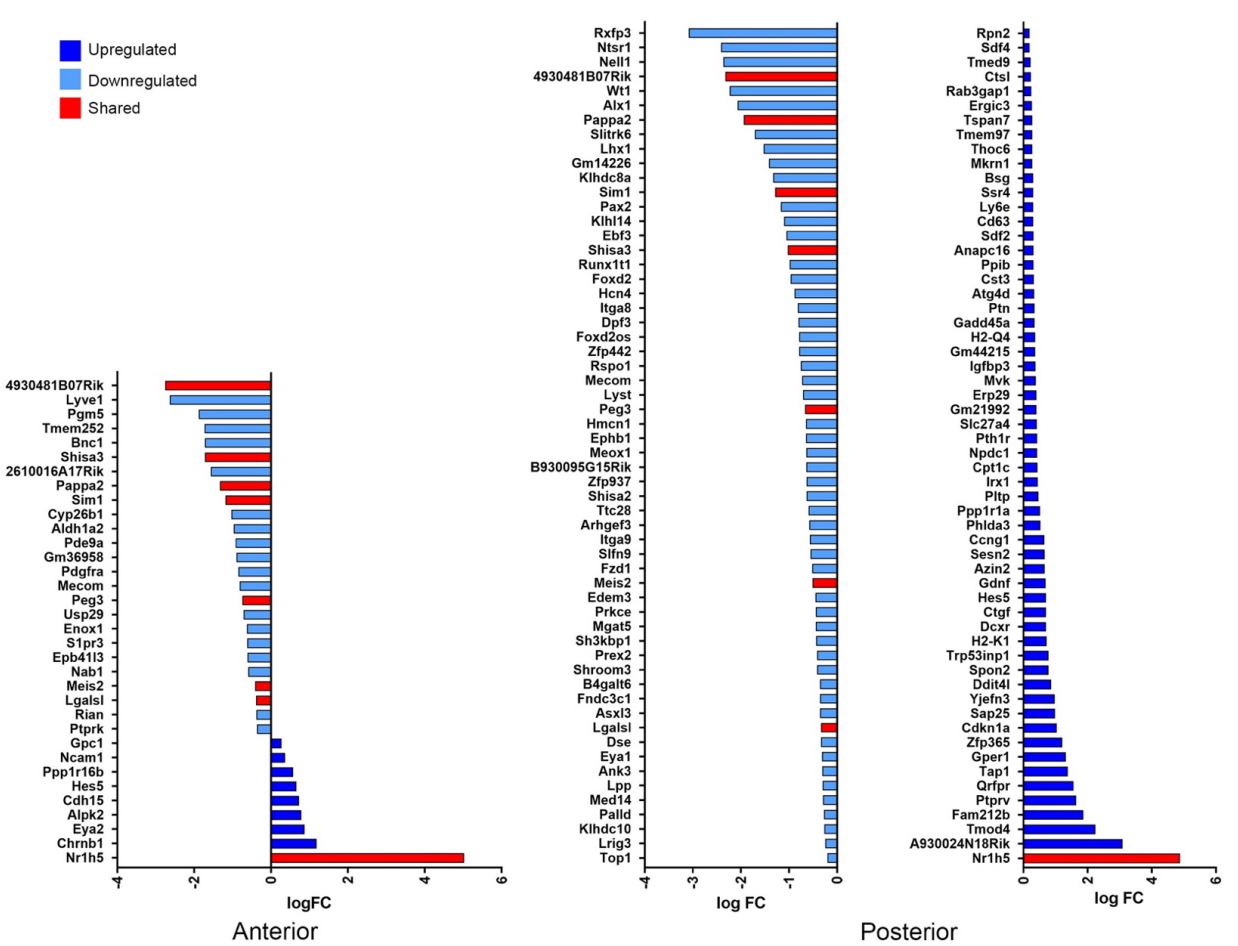

C

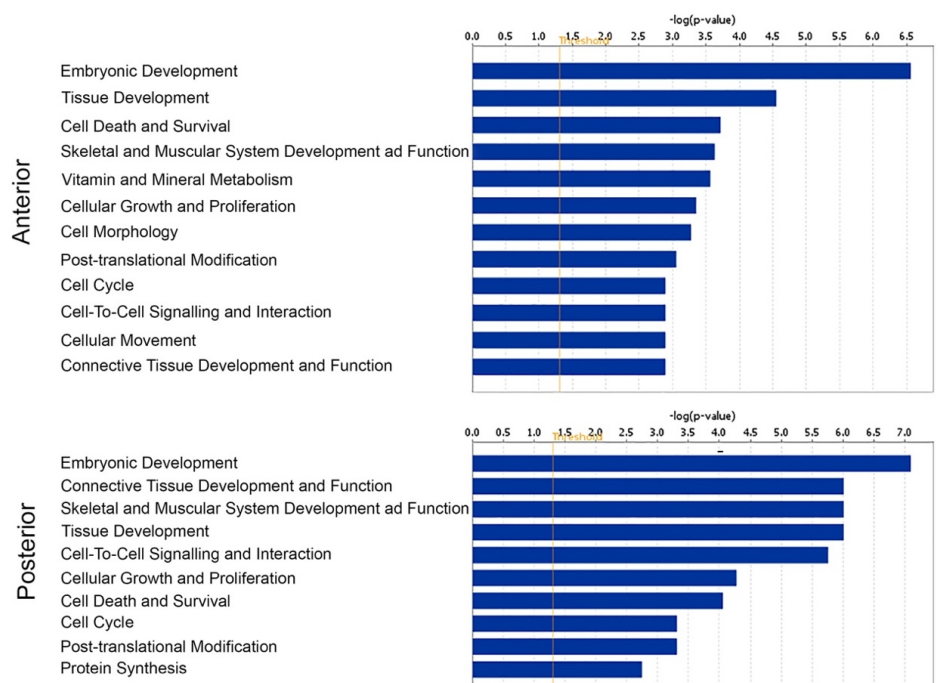

Figure S4. Comparative transcriptomic analysis of $D I l 1^{\mathrm{Cre}} ; M e i s 1^{\mathrm{fff}} ; M e i s 2^{\mathrm{fff}}$ and control embryos at E9.
(A) Representation of the number of genes differentially expressed in both anterior and posterior samples (adjusted p-value $\leq 0.05$ ). (B) Fold change representation (adjusted $\mathrm{p}$-value $\leq 0.05$ ) from anterior and posterior samples (upregulated and downregulated genes are colored in dark and light blue, respectively). Genes colored in red are differentially expressed in both, anterior and posterior. (C) Functions affected in $D / 11^{\text {Cre }} ;$ Meis $1^{\mathrm{fff}} ;$ Meis $2^{\mathrm{fff}}$ embryos from the Ingenuity Pathway analysis in anterior and posterior regions. 
Figure S5. Frequency of recombination induced by $D / 11^{\text {Cre }}$ in the paraxial mesoderm.

The graph shows the frequency of recombined cells measured in the 3 newly formed somites of E8.5-E10.5 DII1 ${ }^{\text {Cre }}$;Rosa26R ${ }^{\text {Tomato }}$ embryos wild type for Meis1 and Meis2 (controls) or carrying the Meis $1^{f}$ and Meis $2^{f}$ alleles in homozygosity (Meis1/2 DKO). Graphs show individual measurements, the median and the $95 \%$ confidence interval.
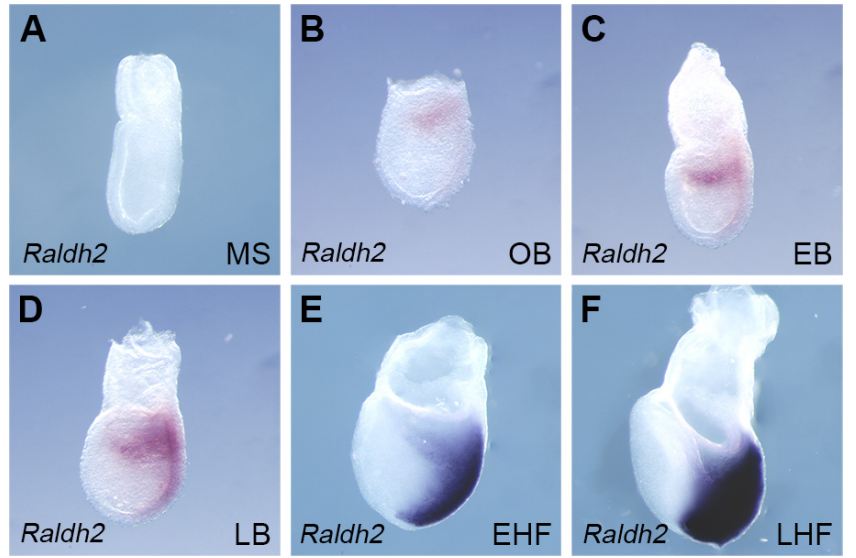

Figure S6. Raldh2 expression pattern in early embryo.

(A-F) Whole-mount mRNA in situ hybridization of Raldh2 from E7 to E7.75. MS, midstreak; OB, no allantoid bud; EB, early allantoid bud; LB, late allantoid bud; EHF, early headfold; LHF, late headfold. All images are oriented with the anterior to the left. 
Table S1A. Scoring of skeletal defects in Conditional deletion of Meis2 using different Cre drivers

\begin{tabular}{|l|c|c|c|}
\hline \multicolumn{1}{|c|}{ PHENOTYPES } & Sox2Cre;M2-/- & Mesp1Cre;M2-/- & DII1Cre;M2-/- \\
\hline \multicolumn{1}{|c|}{ Abnormalities cervical vertebra } & & & \\
\hline C1 fused to E unilateral & 1 & 3 & 1 \\
\hline C1 fused to E bilateral & 13 & 3 & 0 \\
\hline C1 NA approaching E unilateral & 0 & 2 & 1 \\
\hline C1 NA approaching E bilateral & 0 & 1 & 3 \\
\hline C2 with C1-like morphology unilateral & 2 & 2 & 0 \\
\hline C2 with C1-like morphology bilateral & 11 & 3 & 4 \\
\hline C3 with C2-like morphology unilateral & 1 & 0 & 0 \\
\hline C3 with C2-like morphology bilateral & 1 & 0 & 0 \\
\hline Less than 7 cervical vertebra & 0 & 2 & 0 \\
\hline Other abnormalities & 10 & 4 & 3 \\
\hline & & & 0 \\
\hline Rib defects & 3 & 0 & 0 \\
\hline R1 short unilateral & 5 & 0 & 3 \\
\hline R1 short and fused R2 unilateral & 4 & 0 & 1 \\
\hline R1 fused R2 unilateral & 0 & 0 & 0 \\
\hline R1 fused R2 bilateral & 1 & 0 & 0 \\
\hline R13 short & 6 & 1 & 2 \\
\hline Other rib fusions/splits & 5 & 2 & 3 \\
\hline Vestigial rib on L1 & 4 & 1 & 0 \\
\hline sternal/floating ribs 6/7 unilateral & 1 & 0 & 2 \\
\hline sternal/floating ribs R6/7 bilateral & 2 & 0 & 2 \\
\hline \multicolumn{1}{|c|}{ Sternum defects } & 5 & 1 & 0 \\
\hline No of embryos & $\mathbf{1 4}$ & 9 & 4 \\
\hline
\end{tabular}

The table shows the scoring of the observed skeletal defects. B, basioccipital; aaa, anterior arch of the atlas; C, cervical vertebra; NA, neural arches; E, exoccipital; Vb, vertebra; R, rib; L, lumbar vertebra. Number of studied embryos is indicated in parenthesis when it is different from the total.

* Includes misshaping, split neural arches, extra-elements in the cervical region and mismatch in the posterior arch. 
Table S1B. Scoring of skeletal defects in conditional deletion of Meis1 and Meis2 with DII1 ${ }^{\text {cre }}$

\begin{tabular}{|c|c|c|c|c|c|c|c|}
\hline & \multicolumn{7}{|c|}{ Dll1Cre; Meis1; Meis2 } \\
\hline PHENOTYPES & M1-/-M2-/- & $\mathrm{M} 1+/-\mathrm{M} 2-/-$ & M1-/-M2+/- & $\mathrm{M} 1+/-\mathrm{M} 2+/-$ & M1-/-M2+/+ & $\mathrm{M} 1+/+\mathrm{M} 2-/$ & CONTROL \\
\hline \multicolumn{8}{|l|}{ Abnormalities occipital bones } \\
\hline Supraoccipital reduction & $3(3)$ & $7(11)$ & $3(4)$ & $0(2)$ & $1(3)$ & $4(4)$ & $0(23)$ \\
\hline Basioccipital misshaping & $0(3)$ & $7(11)$ & $1(4)$ & $0(2)$ & $0(3)$ & $4(4)$ & $0(23)$ \\
\hline Basioccipital fusion to aaa & & $6(7)$ & $1(1)$ & & & $1(4)$ & \\
\hline Exoccipital & 7 & 5 & 0 & 0 & 0 & 0 & 0 \\
\hline \multicolumn{8}{|l|}{ Abnormalities vertebra 1} \\
\hline C1 NA short unilateral & 0 & 0 & 1 & 0 & 0 & 0 & 0 \\
\hline C1 NA short bilateral & 1 & 1 & 0 & 0 & 0 & 3 & 0 \\
\hline $\mathrm{C} 1$ short and fused to $\mathrm{E}$ unilateral & 0 & 4 & 0 & 0 & 0 & 1 & 0 \\
\hline C1 fused to E bilateral & 0 & 0 & 0 & 0 & 0 & 0 & 0 \\
\hline C1 fused to E bilateral & 6 & 7 & 0 & 0 & 0 & 0 & 0 \\
\hline C1 NA approaching E unilateral & 0 & 4 & 0 & 0 & 0 & 1 & 0 \\
\hline C1 NA approaching E bilateral & 1 & 0 & 0 & 0 & 0 & 3 & 0 \\
\hline \multicolumn{8}{|l|}{ Abnormalities vertebra 2} \\
\hline $\mathrm{C} 2$ fused to $\mathrm{C} 1$ unilateral & 1 & 0 & 0 & 0 & 0 & 0 & 0 \\
\hline C2 fused to $\mathrm{C} 1$ bilateral & 1 & 0 & 0 & 0 & 0 & 0 & 0 \\
\hline Forming aaa & $1(3)$ & $4(11)$ & $1(4)$ & $0(2)$ & $1(3)$ & $3(4)$ & $0(23)$ \\
\hline C1-like morphology unilateral & 1 & 3 & 0 & 0 & 0 & 0 & 0 \\
\hline C1-like morphology bilateral & 1 & 9 & 0 & 0 & 0 & 4 & 0 \\
\hline \multicolumn{8}{|l|}{ Abnormalities vertebra 3} \\
\hline C3 fused to $\mathrm{C} 2$ unilateral & 1 & 3 & 1 & 0 & 0 & 0 & 0 \\
\hline \multicolumn{8}{|c|}{ Other abnormalities cervical vertebrae } \\
\hline Fusions & 6 & 4 & 1 & 1 & 2 & 0 & 0 \\
\hline Other (1) & 3 & 16 & 6 & 1 & 1 & 3 & 2 \\
\hline \multicolumn{8}{|l|}{ Tuberculi anterior } \\
\hline Absence & $0(3)$ & $1(11)$ & $0(4)$ & $0(2)$ & $0(3)$ & $0(4)$ & $0(23)$ \\
\hline \multicolumn{8}{|l|}{ Rib defects } \\
\hline R1 short bilateral & 2 & 8 & 5 & 0 & 0 & 3 & 0 \\
\hline R1 short and fused R2 unilateral & 1 & 5 & 2 & 0 & 0 & 1 & 0 \\
\hline Other rib fusions/splits & 5 & 7 & 6 & 0 & 2 & 3 & 0 \\
\hline Not reaching sternum & 4 & 8 & 5 & 0 & 1 & 2 & 0 \\
\hline sternal/floating ribs $6 / 7$ unilateral & 0 & 3 & 1 & 0 & 1 & 2 & 4 \\
\hline sternal/floating ribs $6 / 7$ bilateral & 0 & 2 & 2 & 1 & 0 & 2 & 0 \\
\hline Vestigial rib on L1 & 0 & 2 & 0 & 0 & 0 & 0 & 1 \\
\hline Sternum defects & 5 & 2 & 0 & 1 & 0 & 0 & 0 \\
\hline Total № of embryos & 7 & 22 & 12 & 8 & 4 & 4 & 46 \\
\hline
\end{tabular}

The table shows the scoring of the observed skeletal defects. B, basioccipital; aaa, anterior arch of the atlas; $\mathrm{C}$, cervical vertebra; NA, neural arches; E, exoccipital; Vb, vertebra; R, rib; L, lumbar vertebra. Number of studied embryos is indicated in parenthesis when it is different from the total.

(1) Includes misshaping, split neural arches, extra-elements in the cervical region and mismatch in the posterior arch.

Table S1C. Statistical analysis of data in S1B

\section{Dll1Cre; Meis1; Meis2}

\begin{tabular}{|c|c|c|}
\hline PHENOTYPES & Control & M1-/-M2+/- \\
\hline Any occipital defect & $0(23)$ & $3(4)^{* *}$ \\
\hline Any cervical defect & $2(46)$ & $4(12)^{*}$ \\
\hline Any thoracic defect & $4(46)$ & $10(12)^{*}$ \\
\hline
\end{tabular}

We used a Fisher test to compare proportions of given features between

groups of fetuses of different groups

${ }^{*}$ pvalue $<0.05 ;{ }^{* *}$ pvalue $<0.01$ 
Table S1D. Scoring of skeletal defects in conditional deletion of Raldh2 with DII1 ${ }^{\text {Cre }}$

\begin{tabular}{|c|c|c|c|c|}
\hline \multirow[b]{2}{*}{ PHENOTYPES } & \multicolumn{3}{|c|}{ Dll1Cre; Raldh2 } & \multirow{2}{*}{$\begin{array}{c}\text { Dll1Cre; Raldh2;R26RMeis2 } \\
-/- \\
\end{array}$} \\
\hline & $-1-$ & $+/-$ & $+/+$ & \\
\hline \multicolumn{5}{|l|}{ Abnormalities occipital bones } \\
\hline Supraoccipital reduction & $2(25)$ & $0(8)$ & $4(33)$ & $0(6)$ \\
\hline Basioccipital misshaping & $14(43)$ & $0(8)$ & $5(39)$ & $0(6)$ \\
\hline Basioccipital fusion to aaa & $7(14)$ & & $4(5)$ & $0(6)$ \\
\hline Exoccipital misshaping & 3 & 0 & 0 & $0(6)$ \\
\hline \multicolumn{5}{|l|}{ Abnormalities vertebra 1} \\
\hline C1 NA short unilateral & 5 & 0 & 0 & $0(6)$ \\
\hline C1 NA short bilateral & 2 & 0 & 0 & $0(6)$ \\
\hline $\mathrm{C} 1$ short and fused to $\mathrm{E}$ unilateral & 1 & 0 & 0 & $0(6)$ \\
\hline$C 1$ fused to $E$ unilateral & 2 & 0 & 0 & $0(6)$ \\
\hline C1 fused to E biilateral & 3 & 0 & 0 & $0(6)$ \\
\hline C1 NA approaching E unilateral & 2 & 0 & 0 & $0(6)$ \\
\hline \multicolumn{5}{|l|}{ Abnormalities vertebra 2} \\
\hline $\mathrm{C} 2$ fused to $\mathrm{C} 1$ unilateral & 8 & 0 & 2 & $0(6)$ \\
\hline $\mathrm{C} 2$ fused to $\mathrm{C} 1$ bilateral & 1 & 0 & 0 & $0(6)$ \\
\hline Forming aaa & $14(41)$ & $0(8)$ & $0(38)$ & $0(6)$ \\
\hline C1-like morphology unilateral & 2 & 0 & 0 & $0(6)$ \\
\hline C1-like morphology bilateral & 6 & 0 & 0 & $0(6)$ \\
\hline \multicolumn{5}{|l|}{ Abnormalities vertebra 3} \\
\hline C3 fused to $\mathrm{C} 2$ unilateral & $10(41)$ & $0(8)$ & $1(38)$ & $0(6)$ \\
\hline C3 fused to C2 bilateral & $1(41)$ & $0(8)$ & $0(38)$ & $0(6)$ \\
\hline \multicolumn{5}{|l|}{ Abnormalities cervical vertebra } \\
\hline Fusions & 10 & 0 & 0 & $0(6)$ \\
\hline Other (1) & 12 & 1 & 2 & $0(6)$ \\
\hline \multicolumn{5}{|l|}{ Tuberculi anterior } \\
\hline Absence & $1(21)$ & $0(8)$ & $0(25)$ & 1(6) unilateral \\
\hline Relocated to Vb7 unilateral & $4(21)$ & $0(8)$ & $2(25)$ & $0(6)$ \\
\hline Relocated to $\mathrm{Vb7}$ bilateral & $1(21)$ & $0(8)$ & $0(25)$ & $0(6)$ \\
\hline \multicolumn{5}{|l|}{ Rib defects } \\
\hline R1 short unilateral & 2 & 0 & 0 & $0(6)$ \\
\hline R1 short and fused R2 unilateral & 2 & 0 & 0 & $0(6)$ \\
\hline R1 fused R2 bilateral & 5 & 0 & 1 & $0(6)$ \\
\hline Other rib fusions/splits & 7 & 0 & 0 & $0(6)$ \\
\hline Not reaching sternum & 4 & 0 & 0 & $0(6)$ \\
\hline sternal/floating ribs $8 / 5$ unilateral & 7 & 0 & 5 & $2(6)$ \\
\hline sternal/floating ribs $8 / 5$ bilateral & 8 & 1 & 9 & $1(6)$ \\
\hline sternal/floating ribs $6 / 7$ unilateral & 1 & 0 & 0 & $0(6)$ \\
\hline vestigial rib on L1 & 5 & 0 & 2 & 1(6) unilateral \\
\hline Sternum defects & 1 & 0 & 0 & $0(6)$ \\
\hline № of embryos & 49 & 15 & 42 & 6 \\
\hline
\end{tabular}

The table shows the scoring of the observed skeletal defects. B, basioccipital; aaa, anterior arch of the atlas; $C$, cervical vertebra; NA, neural arches; E, exoccipital; Vb, vertebra; R, rib; L, lumbar vertebra. Number of studied embryos is indicated in parenthesis when it is different from the total.

(1) Includes misshaping, split neural arches, extra-elements in the cervical region and mismatch in the posterior arch.

Table S1E. Statistical analysis of data in S1D

\begin{tabular}{|c|c|c|c|}
\hline & \multicolumn{2}{|c|}{ Dll1Cre; Raldh2 } & Dll1Cre; Raldh2;R26RMeis2 \\
\hline PHENOTYPES & $+/-\mathrm{OR}+/+$ & $\digamma-$ & $\digamma-$ \\
\hline Any cervical defect & $6(58)$ & $33(49)^{* * *}$ & $0(6)^{* *}$ \\
\hline Cervical transformations & $3(58)$ & $24(49)^{* * *}$ & $0(6)^{*}$ \\
\hline Any thoracic defect & $7(58)$ & $33(49)^{* * *}$ & $0(6)^{* *}$ \\
\hline
\end{tabular}

We used a Fisher test to compare proportions of given features between groups of fetuses

${ }^{*}$ pvalue $<0.05 ;{ }^{* *}$ pvalue $<0.01 ;{ }^{* * *}$ pvalue $<0.001$ 
Table S2. Probes used for whole-mount in situ hybridization

\begin{tabular}{|c|c|c|}
\hline \multicolumn{3}{|r|}{ PCR-amplified from cDNA } \\
\hline Probe & & Primers \\
\hline \multirow[t]{2}{*}{ Hoxal } & Forward & ATTTAGGTGACACTATAGAATGCCATCAGACATTTGCAGG \\
\hline & Reverse & GTAATACGACTCACTATAGGGACAGTGTGGAAGGAAAGGGT \\
\hline \multirow[t]{2}{*}{ Hoxa3 } & Forward & ATTTAGGTGACACTATAGAATGCTGGAAAGGCTGTCAGTA \\
\hline & Reverse & GTAATACGACTCACTATAGGGTTAGCGTTCAGTTTGGCCAG \\
\hline \multirow[t]{2}{*}{ Hoxa4 } & Forward & ATTTAGGTGACACTATAGAATATACCCGGCAGCAAGTCTT \\
\hline & Reverse & GTAATACGACTCACTATAGGGAGTACATGTCCCCAGTCAGC \\
\hline \multirow{2}{*}{ Hoxd4 } & Forward & ATTTAGGTGACACTATAGAATTCGGTGAACCCCAACTACA \\
\hline & Reverse & GTAATACGACTCACTATAGGGGCCTCCAACCTTCATTTGCA \\
\hline \multirow[t]{2}{*}{ Hoxa5 } & Forward & ATTTAGGTGACACTATAGAAGCTGCACATTAGTCACGACA \\
\hline & Reverse & GTAATACGACTCACTATAGGGGCAACACACAACATTGGCAC \\
\hline \multirow[t]{2}{*}{ Hoxa6 } & Forward & ATTTAGGTGACACTATAGAACGGACAAGACATACACCTCAC \\
\hline & Reverse & GTAATACGACTCACTATAGGGCTGCGTGGAGTTGATGAGTT \\
\hline \multirow[t]{2}{*}{ Eyal } & Forward & ATTTAGGTGACACTATAGAAACCGTGTCTGGGATTCTTGT \\
\hline & Reverse & GTAATACGACTCACTATAGGGGGCCATTTCTGTCTGCATCA \\
\hline \multirow[t]{2}{*}{ Sim 1} & Forward & ATTTAGGTGACACTATAGAAGGAAAGGGCAGAGCAGAGTA \\
\hline & Reverse & GTAATACGACTCACTATAGGGGCCTTCAGACCAGATAGCCA \\
\hline \multirow[t]{2}{*}{ Shisa2 } & Forward & ATTTAGGTGACACTATAGAACGATCTTGAACTCCGACCCT \\
\hline & Reverse & GTAATACGACTCACTATAGGGAGTGACAGCGGACAACCTAT \\
\hline \multirow[t]{2}{*}{ FGF6 } & Forward & ATTTAGGTGACACTATAGAATCCACGACGAATGCAAGTTC \\
\hline & Reverse & GTAATACGACTCACTATAGGGTACACACCATGCAGTCCAGT \\
\hline \multirow[t]{2}{*}{ Paxl } & Forward & ATTTAGGTGACACTATAGAAAGATGGCTGCGTTCTCCTAA \\
\hline & Reverse & GTAATACGACTCACTATAGGGCGCGGATTGAAGAAGTCGAG \\
\hline \multirow[t]{2}{*}{ Pax3 } & Forward & ATTTAGGTGACACTATAGAACAATGGCCTTTCACCTCAGG \\
\hline & Reverse & GTAATACGACTCACTATAGGGTCTGTGTCCTGGGCTTATCC \\
\hline \multirow[t]{2}{*}{$\operatorname{Pax} 9$} & Forward & ATTTAGGTGACACTATAGAAATGGATTGGAGAAGGGAGCC \\
\hline & Reverse & GTAATACGACTCACTATAGGGGCACGTTTCGAAAGTTCAGG \\
\hline \multirow[t]{2}{*}{ Myf5 } & Forward & ATTTAGGTGACACTATAGAATACCATGGATCGGCGCAA \\
\hline & Reverse & GTAATACGACTCACTATAGGGGTATTCTGCCCAGCTTGTC \\
\hline \multirow{2}{*}{ MRF4 } & Forward & ATTTAGGTGACACTATAGAATCTGATCTGGGCTTGCAAGA \\
\hline & Reverse & GTAATACGACTCACTATAGGGACTTGAGGTGGTGAGAAGTTTC \\
\hline \multirow[t]{2}{*}{ Myogenin } & Forward & ATTTAGGTGACACTATAGAACATCCAGTACATTGAGCGCC \\
\hline & Reverse & GTAATACGACTCACTATAGGGGTCAGGGCACTCATGTCTCT \\
\hline \multirow[t]{2}{*}{ MyoD } & Forward & ATTTAGGTGACACTATAGAATGGTTCTTCACGCCCAAAAG \\
\hline & Reverse & GTAATACGACTCACTATAGGGAGGGCTCCAGAAAGTGACAA \\
\hline \multicolumn{3}{|r|}{ Synthesized from plasmids } \\
\hline Probe & & Reference \\
\hline Meis 1 & & cDNA nucleotides +439 to +1491 \\
\hline Meis 2 & & cDNA nucleotides +532 to +999 \\
\hline Cyp26b1 & & cDNA nucleotides +120 to +1034 \\
\hline$F G F 4$ & & Provided by J. L. de la Pompa \\
\hline Raldh2 & & Provided by P. Bovolenta \\
\hline$R A R B$ & & Provided by A. Zuniga \\
\hline Hoxb3 & & Provided by R. Krumlauf \\
\hline Hoxc3 & & Provided by R. Krumlauf \\
\hline
\end{tabular}

